\title{
Enriched environment protects against depressive and anxiety-like behaviors in mice after striatal intracerebral hemorrhage
}

\section{Xuemei Chen}

Zhengzhou University

Peijun Jia

Zhengzhou University

Junmin Wang

Zhengzhou University

Xiuhua Ren

Zhengzhou University

Jinxin He

Zhengzhou University

Shaoshuai Wang

Zhengzhou University

Yinpei Xing

Zhengzhou University

Danyang Chen

Zhengzhou University

Xinling Zhang

Zhengzhou University

\section{Siqi Zhou}

Zhengzhou University

Xi Liu

First Affiliated Hospital of Zhengzhou University

Shangchen Yu

Zhengzhou University

\section{Zefu Li}

Zhengzhou University

Chao Jiang

Fifth Affiliated Hospital of Zhengzhou University

Weidong Zang

Zhengzhou University

Jian Wang ( $\square$ jianwang2020@outlook.com ) 


\section{Research Article}

Keywords: Anxiety behaviors, Brain-derived neurotrophic factor, Enriched environment, Intracerebral hemorrhage, Nuclear regulatory factor 2, Post-stroke depression

Posted Date: February 2nd, 2022

DOI: https://doi.org/10.21203/rs.3.rs-1304908/v1

License: (a) (i) This work is licensed under a Creative Commons Attribution 4.0 International License. Read Full License 


\section{Abstract}

Background: Post-stroke depression (PSD) has a negative impact on neurologic outcomes and quality of life. Although depression after ischemic stroke has been studied clinically and preclinically, very little is known about the frequency and severity of depression after intracerebral hemorrhage (ICH). Increasing evidence shows that exposure to an enriched environment (EE) after cerebral ischemia/reperfusion injury has neuroprotective effects in animal models, but its effects after ICH are unknown.

Methods: In this study, we investigated the effects of an EE on long-term functional outcome in mice subjected to a collagenase-induced striatal ICH model. Mice were subjected to ICH only or ICH with EE for $6 \mathrm{~h} /$ day (8:00 am-2:00 pm). Depressive- and anxiety-like behaviors were evaluated on day 28 with the sucrose preference test, tail suspension test, forced swim test, and light-dark transition experiment.

Results: EE exposure reduced brain edema, improved neurologic function, attenuated depressive- and anxiety-like behaviors, promoted spatial learning and memory, increased the expression of transcription factor Nrf2 and brain-derived neurotrophic factor (BDNF), and inhibited glutaminase activity in the ICH brain. However, in $\mathrm{Nrf2}^{-/-}$mice with ICH, EE did not mitigate depression-like behaviors on day 28.

Conclusions: These findings indicate that EE improves long-term sensorimotor, emotional, and cognitivebehavior outcomes after ICH and that the underlying mechanism involves the Nrf2/BDNF/glutaminase pathway.

\section{Background}

Post-stroke depression (PSD) is a common, chronic, and recurrent problem that affects $30-35 \%$ of patients in the first year after stroke[1, 2]. It impairs neurologic and cognitive function [3], quality of life[4], and mortality[5]. More than $20 \%$ of patients who survive hemorrhagic stroke have a depressed mood at 3 months. This depression leads to an overall poor quality of life [6]. However, clinical, preclinical, and translational research on intracerebral hemorrhage $(\mathrm{ICH})$-induced depression is scarce. Furthermore, its pathomechanism is poorly understood. Therefore, identifying promising therapies to target depression and understanding the specific pathogenesis of depression after $\mathrm{ICH}$ is vital for improving clinical outcomes.

Environmental enrichment in housing can improve the mental and physical health of laboratory mice [7, 8]. Striking evidence suggests that an enriched environment (EE) promotes neuronal growth, restructuring, and recovery after the central nervous system (CNS) injury $[9,10]$. However, although EE exposure provides neuroprotection after ischemic stroke, its effects on post-ICH depression and the underlying mechanisms are unknown.

The interaction between depression and stroke is complex[11]. Both conditions involve inflammation, oxidative stress, autophagy, and various forms of cell death $[3,12,13]$. Six major pathways are considered be dysregulated in depression, including inflammatory cell-mediated immune, oxidative, 
mitochondrial, antioxidant (lowered levels of glutathione), and neuroprogressive pathways[14]. With marked effects on all six pathways, the nuclear factor erythroid 2-related factor 2 (Nrf2) signaling pathway might be involved in developing PSD[14]. We have reported previously that injury volume is significantly larger in $\mathrm{Nrf2}^{-/-}$mice than in wild-type controls after collagenase-induced striatal ICH[15]. Our new study showed that down-regulation of the Nrf2-BDNF signaling pathway contributes to the development of cortical hemorrhage-induced depression[16]. Brain-derived neurotrophic factor (BDNF), which has been implicated in the pathophysiology of depressive disorders[13], is known to regulate neurogenesis, synaptogenesis, and angiogenesis and promote neuronal survival[6]. In particular, BDNF is an Nrf2 target gene, and Nrf2/BDNF signaling is involved in the antidepressant-like effect of agmatine and fluoxetine[17]. In addition, behavioral abnormalities are associated with altered glutamate signaling[18]. Glutaminase, the CNS enzyme that produces glutamate from glutamine, plays a vital role in generating toxic glutamate[19]. Although BDNF and glutaminase expression changes might be associated with altered depression-like behaviors in other animal models, their role in post-ICH depression has not been reported.

Therefore, in this study, using a mouse model of $\mathrm{ICH}$, we evaluated whether an EE attenuates neurologic deficits, cognitive deficits, and depressive- and anxiety-like behavior and whether the Nrf2/BDNF/glutaminase signaling pathway is involved.

\section{Materials And Methods}

\section{Mice}

A total of 228 10-month-old C57BL/ 6 male mice (30-35 g) and 27 Nrf2- ${ }^{-1-}$ mice (3-month-old, 20-25 g) were used in our study. Mice were purchased from the Beijing Vital River Laboratory Animal Technology Co. Ltd. (NO.11400700282075) and housed in a specific pathogen-free environment with a 12h light-dark cycle and controlled temperature $\left(24 \pm 1^{\circ} \mathrm{C}\right)$ and relative humidity $(60 \pm 10 \%)$. Nrf2 ${ }^{-/-}$mice were generated by Dr. Masayuki Yamamoto (on a C57BL/ 6 background). Genotype was determined by PCR amplification of genomic DNA extracted from tail snips of the mice. Three to five mice per cage were housed with free access to standard food and water. All animal protocols were approved by the Animal Ethics Committee of Zhengzhou University. All experiments were performed and reported according to the Guide for the Care and Use of Laboratory Animals, 8th edition (2011) and the ARRIVE guidelines

(http://www.nc3rs.org.uk/arrive-guidelines). All mice were randomly assigned to different groups by using the randomizer form at http://www.randomization.com[20, 21].

\section{ICH mouse model}

Mice were anesthetized with isoflurane $\left(70 \% \mathrm{~N}_{2} \mathrm{O}\right.$ and $30 \% \mathrm{O}_{2}, 4 \%$ induction, $2 \%$ maintenance) and placed in a stereotaxic frame for aseptic surgery. A 1-cm long incision was made over the midline of the scalp. A mouse adaptor was used to drill a borehole $2 \mathrm{~mm}$ left and $0.5 \mathrm{~mm}$ anterior to the bregma, with a depth of $3.1 \mathrm{~mm}$. ICH was induced by injecting collagenase VII-S (sterile-filtered, relatively endotoxin-free, $0.05 \mathrm{U}$ in 
$0.5 \mu \mathrm{L}$ sterile saline, Sigma, St. Louis, MO) into the left striatum as previously described[22, 23]. The collagenase was infused with a micro-infusion pump at a constant rate of $0.1 \mu \mathrm{L} / \mathrm{min}$. Body temperature was maintained at $37 \pm 0.5^{\circ} \mathrm{C}$ during surgery. After surgery, the mice were returned to their home cages. The sham control group underwent a surgical incision but was infused with saline. Animals that died or were euthanized within $24 \mathrm{~h}$ after surgery were excluded from the sample size. Otherwise, all animals proceeded into the final analysis.

\section{EE conditions}

On day 1 after surgery, mice in the ICH+EE group were housed in a box with an enriched environment that we made ourselves $(120 \mathrm{~cm} \times 90 \mathrm{~cm} \times 76 \mathrm{~cm}$ ) based on a published method[24]. The box contained two mouse cages with food and water, running wheels, igloos with saucer wheels, plastic tubing, and other toys (Supplementary Fig. 1). Six to eight mice were housed in an EE box for $6 \mathrm{~h} /$ day (8:00 am-2:00 pm) until day 28 after ICH (Supplementary video) [25]. The devices were rearranged and renewed every day to stimulate the exploratory behavior of the animals and to maintain the novelty of the environment. Control to ICH+EE mice and sham mice were housed in groups of 3 to 5 in standard cages (30 $\mathrm{cm} \mathrm{x} 45 \mathrm{~cm} \times 20$ $\mathrm{cm}$ ) without toys, defined as a standard environment (SE). All animals had free access to food and water. The items that were used in EE included: 1) two cross pipes (interface diameter: $5.5 \mathrm{~cm}$ ), 2) eight straight pipes (interface diameter: $5.5 \mathrm{~cm}$ ), 3) six frisbee running wheels (diameter: $18 \mathrm{~cm}$, height:11 cm), 4) six windmill running wheels (diameter: $13 \mathrm{~cm}$, height: $14.5 \mathrm{~cm}$, width: $7.5 \mathrm{~cm})$, and 5) the large cage $(120 \mathrm{~cm}$ x $90 \mathrm{~cm} \times 76 \mathrm{~cm}$ ) with an EE that was made by the aluminum alloy panel (Zhengzhou Welding Factory, Zhengzhou, China). An illustration of the EE condition of toys is shown in Supplementary Fig. 1 and displayed in Supplementary video 1.

\section{Brain lesion volume}

On day 3 after $\mathrm{ICH}$, the mice were anesthetized with 3\% isoflurane and perfused through the left ventricle with saline followed by $4 \%$ paraformaldehyde. Then the brain was removed. Coronal sections through the entire striatum were stained with Cresyl violet acetate (CV, for Nissl bodies) and Luxol fast blue (for myelin). Image J software was used to quantify the hemorrhagic injury volume. Sections were analyzed by an investigator blind to the experimental cohort as previously described $[22,26]$.

\section{Brain edema measurement}

On day 3 after $\mathrm{ICH}$, mice were sacrificed under deep anesthesia with $3 \%$ isoflurane. Their brains were harvested and dissected along the sagittal fissure into the ipsilateral and contralateral hemispheres and cerebellum. Brain tissue was immediately weighed to get the wet weight and then heated to $100^{\circ} \mathrm{C}$ in a drying oven for $72 \mathrm{~h}$ to obtain the dry weight. We determined brain edema by calculating brain water content as follows: brain water content $(\%)=($ wet weight - dry weight) $/$ wet weight $\times 100 \%[22,26]$.

\section{Neurologic function}


According to a previously published method [23],we tested each mouse for neurologic deficit scores on days $1,3,5,7,14$, and 21 after ICH. Scores were summed on six subtests, body symmetry, gait, climbing, circling behavior, front limb symmetry, and compulsory circling. Each test was ranked from 0 to 4 , establishing a maximum deficit score of 24.

\section{Forelimb and hind limb placing test}

On days $3,5,7,14$, and 21 after ICH, forelimb and hind limb placing tests were carried out based on our previous studies $[23,27,28]$. Mice were placed facing the edge of a desktop and the contralateral hind limb was pulled down. The ability of the mouse to place the hind limb back onto the desktop was quantified as follows: immediate and complete pullback of $\operatorname{limb}=0$, delayed pullback $(>2 \mathrm{~s})=1$, inability to pull back $=2$. Placing was determined in 10 consecutive trials. The video of the forelimb and hindlimb placing tests were displayed in supplementary videos 2,3 .

\section{Corner turn test}

On days $3,5,7,14$, and 21 after $\mathrm{ICH}$, the mouse was directed into a $30^{\circ}$ corner as previously described [20]. The mouse had the option to turn either right or left to exit the corner. The number of turns in each direction was recorded in 10 repeated tests. Then the percentage of right turns was calculated. Normal mice exhibit approximately $50 \%$ of turns in each direction [29].

\section{Morris water maze (MWM)}

The MWM test evaluated spatial learning and memory ability in rodents based on an established standard procedure [30]. The system used consisted of a circular black swimming pool $(120 \mathrm{~cm}$ in diameter), an escape platform ( $10 \mathrm{~cm}$ in diameter) submerged $0.5 \mathrm{~cm}$ under the water surface in the center of one of four imaginary quadrants, and a SMART 3.0 animal behavior analysis system (Panlab, Spain). The mice were released into the pool facing the wall in random positions and had to swim to find the submerged platform. In the training phase, mice underwent 1 trial/day over 4 consecutive days beginning on day 24 . On day 28 , the spatial memory was estimated using trajectory and navigation parameters in the testing phase.

\section{Novel object recognition test}

On days 27 and 28 after $\mathrm{ICH}$, the novel object recognition test was performed according to an established protocol [31]. In short, mice were allowed to explore two identical new objects (violet cubes, $4 \times 4 \times 3 \mathrm{~cm}$ ) in an open field $(47 \times 26 \times 20 \mathrm{~cm})$ for $10 \mathrm{~min}$ on the first day (day 27). The following day (day 28), the mice were exposed to one new object (white ball, $5 \mathrm{~cm}$ in diameter) and one familiar object (violet cube) in the field for $5 \mathrm{~min}$. The behaviors displayed by each mouse were recorded on video. The discrimination index was calculated to assess cognitive ability: Discrimination index $(\%)=$ (total time devoted to new object/total time spent exploring objects) $\times 100 \%$. Exploring object was identified as direct contact with the paw, nose, or mouth, or the nose directed at the object at $<0.5 \mathrm{~cm}$. 


\section{Depression-like behavior}

\section{Forced swim test (FST)}

The FST was conducted according to the previously described method [31]. The swimming apparatus was a glass cylinder $\left(20 \mathrm{~cm}\right.$ high $\times 22 \mathrm{~cm}$ in diameter) containing $10 \mathrm{~cm}$ of water at $24 \pm 1^{\circ} \mathrm{C}$. On day 28 after $\mathrm{ICH}$, mice were forced to swim for $6 \mathrm{~min}$, and the duration of immobility in the last 4 min was video recorded. The mice were defined as immobile when they were motionless or made only slight movements to maintain their head above the water.

\section{Tail suspension test (TST)}

The TST was carried out on day 28 after ICH as previously described [32,33]. Each mouse was placed in the testing room for a period of acclimatization (generally at least $1 \mathrm{~h}$ ) prior to the behavioral procedure. The mice were individually suspended by the tail from a bar $55 \mathrm{~cm}$ above the floor with a piece of adhesive tape (17 cm long, $2 \mathrm{~cm}$ from the tip of the tail). A polycarbonate tube $(4 \mathrm{~cm}$ in length, $1 \mathrm{~cm}$ in diameter, $1.5 \mathrm{~g}$ ) was placed around the tail to prevent mice from climbing their tails. A camera was used to record the movement of the mice for $6 \mathrm{~min}$, and the duration of immobility was calculated.

\section{Sucrose preference test (SPT)}

The SPT evaluated anhedonia based on an established protocol [31]. On day 25, mice were placed into separate cages with two bottles, one containing water and the other a $1 \%$ sucrose solution. The bottles were weighed at the start of the test, and their positions in the cage were changed daily. On day 28 , the two bottles were reweighed and the amount of liquid consumed was measured. The sucrose preference was calculated as a percentage of the sucrose solution consumed relative to the total amount of liquid consumed: sucrose preference $(\%)=$ sucrose consumption $(\mathrm{g}) /[$ water consumption $(\mathrm{g})+$ sucrose consumption (g)].

\section{Light/dark transition test}

On day 28, a light/dark transition test was performed as previously described [34]. The apparatus consisted of a cage $(100 \mathrm{~cm})$ divided into two chambers of equal size by a barrier with a door. One chamber was light and the other dark. The mice were placed in the dark chamber and allowed to move without restraint between the two chambers through the door for $10 \mathrm{~min}$. The total number of times the mouse traversed, and the time spent in each chamber (seconds) were analyzed by a SMART 3.0 animal behavior analysis system.

\section{Anxiety-like behavior}

\section{Open Field Test}

On day 28, the open field test was used to assess anxiety [35]. Each mouse was allowed to acclimate to the testing room for $2 \mathrm{~h}$ before the test. Then it was placed into the center of the open field box to explore 
freely for $5 \mathrm{~min}$. After each test, we used alcohol to clean the box to prevent smells from influencing the behavior of the next mouse. Smart Video Tracking Software was used to track and analyze each mouse's movements. The time spent and the distance traveled in the center and the periphery of the box was analyzed [36].

\section{Elevated Plus-Maze (EPM)}

The EPM is one of the most extensively used tests to assess anxiety-like behavior in mice [37]. The apparatus consists of a pair of open arms $(50 \mathrm{~cm} \times 5 \mathrm{~cm})$ perpendicular to a pair of arms with walls but no ceiling $(50 \mathrm{~cm} \times 10 \mathrm{~cm} \times 40 \mathrm{~cm})$ and a connected central area $(10 \mathrm{~cm} \times 10 \mathrm{~cm})$. The maze is situated $50 \mathrm{~cm}$ above the ground. The mouse was placed into the center of the maze facing one of the closed arms and allowed to explore for $5 \mathrm{~min}$. A computer recorded the number of times the mice entered open and closed arms and the time spent in the open and closed arms. An arm entry was defined as a mouse having all four legs in one arm of the maze.

\section{Western blot analysis}

On day 28, Western blotting was performed to evaluate Nrf2 and BDNF protein expression levels in the mouse brain the injured area [30,38]. Brain tissues collected from around the injured area were lysed in ice-cold lysis buffer (RIPA: PMSF=100:1) with a protease inhibitor cocktail. A bicinchoninic acid (BCA) assay kit (PC0020, Solarbio Science\& Technology Co, Ltd. Beijing) was used to measure the protein concentration. We separated $35 \mu \mathrm{g}$ of protein from each sample by SDS-PAGE and transferred the proteins to nitrocellulose membranes. After being blocked with nonfat milk for $2 h$, the membranes were incubated with primary antibodies against Nrf2 (1:1000, Abcam, Cambridge, MA), BDNF (1:500, Abcam), and tubulin $(1: 250, A b c a m)$ at $4^{\circ} \mathrm{C}$ overnight. Subsequently, the membranes were incubated with HRPlabeled anti-mouse or anti-rabbit secondary antibodies (1:10,000, Santa Cruz, Dallas, TX) at room temperature for $2 \mathrm{~h}$. The immunoglobulins were then detected with a FluorChem imaging system (San Jose, $C A$ ) with the enhanced chemiluminescence (ECL) technique. Image $\mathrm{J}$ software was used to normalize the intensities of the target bands to those of the corresponding loading control.

\section{Immunofluorescence staining}

Immunofluorescence was carried out as previously described [39]. Three mice in each group were anesthetized with an overdose of $10 \%$ chloral hydrate and transcardially perfused through the left ventricle with saline followed by $4 \%$ paraformaldehyde on day 28 . Brains were dissected out, post-fixed in $4 \%$ paraformaldehyde for $24 \mathrm{~h}$, and then dehydrated with $20 \%$ and $30 \%$ sucrose successively. The brain tissues were serially sectioned into $20-\mu \mathrm{m}$-thick sections with a freezing microtome (Leica CM1950, Germany). The sections were blocked with $5 \%$ goat serum in phosphate-buffered saline with $0.1 \%$ Triton$\mathrm{X} 100$ for $2 \mathrm{~h}$ at room temperature. Slices were incubated with rabbit anti-BDNF (1:500, Abcam) primary antibody at $4^{\circ} \mathrm{C}$ overnight followed by Cy3-conjugated goat anti-rabbit IgG secondary antibody (1:100, Boster Biological Technology, Wu Han) for $2 \mathrm{~h}$ at $37^{\circ} \mathrm{C}$. Labeled tissues were counterstained with 4',6diamidino-2-phenylindole (DAPI, D8417, 1:1000, Sigma). The sections were examined and photographed 
with a fluorescence microscope (Olympus Corporation, Tokyo, Japan). Four fields from each section were selected, and five consecutive brain sections were used. The numbers of positive cells in each field were determined, and mean values were calculated from 20 fields to represent BDNF-positive cells in one mouse.

\section{High-Performance Liquid Chromatography (HPLC) analysis}

Ultra-high performance liquid chromatography-tandem triple four-stage mass spectrometry (UPLC-MS) was used to measure glutamate concentration in brain tissue from around the hematoma on day 28 after $\mathrm{ICH}$ [40]. Brain tissue collected around the hematoma (approximately $3 \mathrm{~mm}$ thick) was lysed in methanol solution $(7 \mathrm{~g} / \mathrm{ml})$ on ice. It was homogenized by a tissue grinder (XIN-M48, Shanghai Xinwen Scientific Instrument Co., Ltd, Shanghai, China) at the speed of $9424 \mathrm{~g}$ for $1 \mathrm{~min}$. The homogenate was then centrifuged at a speed of $15078 \mathrm{~g}$ for $10 \mathrm{~min}$ and the supernatant was diluted 50 times with $0.5 \%$ formic acid. Next, the mixture was dried by using nitrogen evaporator (N-EVAP, Organomation, MA, USA) at $35^{\circ} \mathrm{C}$ and $100 \mu \mathrm{L}$ initial mobile phase complex $(2.5 \mathrm{~mol} / \mathrm{L}$ ammonium acetate and $0.1 \%$ formic acid) was added as the sampling solution. Glutamate purchased from Sigma-Aldrich was used to create the standard curve. We then injected $2 \mu \mathrm{L}$ of the sampling solution into a Porosell $120 \mathrm{EC}-\mathrm{C} 1$ column (Phenomenex, St. Louis, Missouri) in the HTEC-500. We eluted it with a buffer consisting of $2.5 \mathrm{mmol} / \mathrm{L}$ of ammonium acetate with $0.1 \%$ formic acid solution and acetonitrile with $0.1 \%$ formic acid solution. The peak of neurotransmitter chromatograms was identified by the retention time in the standard solution. The concentration was calculated according to the peak area in the standard solution. The data were analyzed using Chemstation software (Agilent, Santa Clara, USA).

\section{Glutaminase activity}

The tissue around the injured area of the brain was collected on day 28 after ICH, Glutaminase activity was measured with commercial glutaminase activity kits according to the manufacturer's instructions (Nanjing Jiancheng Bioengineering Institute, Nanjing, China).

\section{Statistical analysis}

Data are expressed as means \pm standard deviation (SD), dot plot, or bar graphs. We used a t-test, one-way or two-way ANOVA, and Bonferroni post hoc test to compare differences among multiple groups. A $p<$ 0.05 was considered statistically significant. All analyzes were performed with GraphPad Software (GraphPad Prism 5.0, GraphPad Software, Inc., La Jolla, CA). The outlying data points were defined with statistical software assuming a normal distribution (the threshold was 2.0 times the SD from the mean).

\section{Results}

\section{Effect of EE on mortality after ICH}


The mortality of ICH+EE mice (5 out of 76) was not different from that of ICH+SE mice (5 out of 79). The mortality of the $\mathrm{Nrf2}^{-/-} \mathrm{ICH}+\mathrm{EE}$ mice (1 out of 10 ) did not differ from that of the $\mathrm{Nrf2}{ }^{-1-} \mathrm{ICH}+\mathrm{SE}$ mice (0 out of 9$)$. None of the WT $(n=8)$ or $\mathrm{Nrf2}^{-/-}$mice $(n=8)$ died in the sham group (Supplementary Fig.2).

\section{EE does not decrease acute brain injury after ICH}

We illustrated the sequence and timeline of the experimental procedures in Fig. 1A. The brain water content of the ipsilateral hemisphere tended to be lower in the ICH+EE group than in the ICH+SE group on day 3 after $\mathrm{ICH}$, but the difference was not significant between the two groups $(78.19 \pm 0.70 \%$ vs. $80.63 \pm$ $2.85 \%, \mathrm{n}=5$ mice/group, $\mathrm{F}=3.825, p=0.0519$, Fig. $1 \mathrm{~B})$. In the $\mathrm{ICH}+\mathrm{SE}$ and the $\mathrm{ICH}+\mathrm{EE}$ groups, the myelin showed substantial damage on the ipsilateral side compared to that on the contralateral side (Fig.1C). However, EE did not increase the area with normal myelin around the hematoma, as assessed by Luxol fast blue staining ( $32.08 \pm 5.077 \%$ vs. $39.73 \pm 4.49 \%, n=3$ mice/group, Fig. $1 \mathrm{~F})$. The hemorrhage was predominantly located within the striatum, without extending into other areas of the nucleus (Fig. 1D). Images of fresh brain slices and CV/Luxol fast blue-stained slices showed that the lesion and hematoma volume did not differ significantly between the ICH+SE and ICH+EE groups on day $3\left(7.104 \pm 0.6679 \mathrm{~mm}^{3}\right.$ vs. $6.329 \pm 1.068 \mathrm{~mm}^{3}, 4.587 \pm 0.6796 \mathrm{~mm}^{3}$ vs. $4.508 \pm 0.7632 \mathrm{~mm}^{3}, \mathrm{n}=8$ mice/group, $p>0.05$, Fig. $1 \mathrm{E}$, $\mathrm{G)}$.

\section{EE mitigates neurologic deficits after ICH}

The neurologic deficit scores of mice were significantly elevated on day 3 after $\mathrm{ICH}$ and then gradually decreased in the two ICH groups with time. Compared to ICH+SE mice, those in the ICH+EE group had significantly lower neurologic deficit scores on days $3,5,7$, and 14 after ICH $\left(F_{\text {Interaction }}=30.61\right.$, $\mathrm{F}_{\text {Time }}=166.6, \mathrm{~F}_{\text {Column Factor }}=96.11, \mathrm{~F}_{\text {Subjects }}=3.603, p<0.05, \mathrm{n}=10-13$ mice/group, Fig. $2 \mathrm{~A}$ ). EE also increased the percentage of left turns in the corner turn test on days 3,5 , and 7 after $\mathrm{ICH}$ $\left(F_{\text {Interaction }}=8.693, F_{\text {Time }}=35.20, F_{\text {Column Factor }}=24.29, F_{\text {Subjects }}=3.891, p<0.05, n=13\right.$ mice $/$ group, Fig. 2B). Furthermore, EE significantly improved motor performance in the forelimb and hindlimb placing tests on days 3, 5, and 7 after ICH $\left(F_{\text {Interaction }}=13.21, F_{\text {Time }}=107.7, F_{\text {Column Factor }}=110.4, F_{\text {Subjects }}=0.8559\right.$ and $\mathrm{F}_{\text {Interaction }}=51.77, \mathrm{~F}_{\text {Time }}=236.2, \mathrm{~F}_{\text {Column Factor }}=87.57, \mathrm{~F}_{\text {Subjects }}=3.338$, respectively, $p<0.05, \mathrm{n}=10$ mice/group, Fig. 2Cand 2D).

\section{EE mitigates depression-like behaviors after ICH}

No difference exists in the FST, the light/dark transition test, the open field test, and the novel object recognition test on day 28 among the control group, the sham group, and the control + EE group (Supplementary Fig.3). In both the FST and the TST, the immobility time in the ICH+EE group was significantly shorter than in the ICH+SE group on day $28(177.9 \pm 11.01 \mathrm{~s}$ vs. $225 \pm 44.56 \mathrm{~s}$ in the FST, $254.4 \pm 24.48 \mathrm{~s}$ vs. $289.9 \pm 45.88 \mathrm{~s}$ in the TST, $\mathrm{F}=7.47$ and 5.28 , respectively, both $p<0.05, \mathrm{n}=8$ mice/group, Fig. $3 \mathrm{~A}$ and $3 \mathrm{~B}$ ). Furthermore, in the SPT, the ICH+EE mice consumed more sucrosesweetened water $(70.72 \pm 6.66 \%)$ than did those ICH+SE $(62.5 \pm 8.76 \%, F=21.85, p<0.05, \mathrm{n}=10$ 
mice/group, Fig. 3C), although the total liquid consumed did not differ between the two ICH groups (Supplementary Fig.4). In the light/dark transition test, mice from the ICH+EE group spent significantly more time in the light compartment and less time in the dark box when compared to ICH+SE mice (87.44 $\pm 23.44 \mathrm{~s}$ vs. $38.32 \pm 17.42 \mathrm{~s}$ in light box, $212.9 \pm 23.44 \mathrm{~s}$ vs. $261.7 \pm 17.42 \mathrm{~s}$ in dark box) on day 28 ( $F=8.954$ and 8.954, respectively, $p<0.05, n=8$ mice/group, Fig. 3D and 3E). However, the number of entries into the light box did not differ significantly among the $\mathrm{ICH}+\mathrm{EE}, \mathrm{ICH}+\mathrm{SE}$, and sham groups $(\mathrm{F}=0.09439, p>0.05, \mathrm{n}=8 \mathrm{mice} / \mathrm{group}, \mathrm{Fig} .3 \mathrm{~F})$.

\section{EE reduces anxiety-like behaviors after ICH}

Anxiety-like behaviors improved in mice from the ICH+EE group. In the open field test, mice from the $\mathrm{ICH}+\mathrm{SE}$ group exhibited less activity in the center of the field than did mice from the ICH+EE group (Fig. $4 \mathrm{~A})$, although the mean speed did not differ ( $p>0.05, n=6$ mice/group, Fig. 4B). The percentages of time and distance walked in the center area were greater for mice in the ICH+EE group than for mice in the $\mathrm{ICH}+\mathrm{SE}$ group ( $5.62 \pm 1.27 \%$ vs. $2.83 \pm 1.24 \%$ and $9.94 \pm 1.47 \%$ vs. $4.21 \pm 2.05 \%$, respectively) on day 28 after ICH ( $\mathrm{F}=1.33$ and 7.57, respectively, both $p<0.05, \mathrm{n}=6$ mice/group, Fig.4C and 4D). Similarly, mice in the $\mathrm{ICH}+\mathrm{EE}$ group spent more time in the open arms of the EPM and less in the closed arms when compared to mice in the ICH+SE group $(14.88 \pm 6.93 \%$ vs. $4.5 \pm 2.82 \%$ in the open arms, $61 \pm 16.37 \%$ vs. $82.71 \pm 7.34 \%$ in the closed arms) on day 28 after $\mathrm{ICH}(\mathrm{F}=5.93$ and 9.10 , respectively, both $p<0.05, \mathrm{n}=7$ 8 mice/group, Fig.4E and 4F). Mice in the $\mathrm{ICH}+\mathrm{EE}$ group also made more entries into closed arms than mice in the $\mathrm{ICH}+\mathrm{SE}$ group $(7.75 \pm 1.83$ times vs. $5.37 \pm 1.30$ times, $\mathrm{F}=9.81, p<0.05, \mathrm{n}=8-9$ mice/group, Fig. 4G).

\section{EE improves spatial learning and memory function after ICH}

Representative trajectories in the MWM test for a mouse from each group are shown in Fig. 5A. Mice in the $\mathrm{ICH}+\mathrm{EE}$ group required significantly less time to find the hidden platform than mice in the $\mathrm{ICH}+\mathrm{SE}$ group on days 26,27 , and 28 after ICH (day 25: $55.5 \pm 2.3 \mathrm{~s}$ vs. $60 \pm 0 \mathrm{~s}$ [p>0.05], day $26: 27.1 \pm 4.9 \mathrm{~s}$ vs. $55.7 \pm 1.9 \mathrm{~s}$ [ $p<0.05]$, day $27: 15.9 \pm 2.7 \mathrm{~s}$ vs. $28.8 \pm 2.8 \mathrm{~s}$ [ $p<0.05]$, day $28: 8.9 \pm 2.1 \mathrm{~s}$ vs. $20.3 \pm 2.4 \mathrm{~s}$ [ $p<$ 0.05], $\mathrm{n}=9$ mice/group, Fig. 5B) but the swimming speed did not differ significantly between the three groups during the training period ( $p>0.05, n=9-10$ mice/group, Fig. $5 C$ ). Mice exposed to EE conditions also exhibited a higher frequency of target platform crossings ( $3.5 \pm 1.7$ times) than did those housed in the SE after ICH ( $1.0 \pm 1.1$ times) on day 28 ( $F=9.20, p<0.05, n=9$ mice/group, Fig.5D). In the novel object recognition test, mice in the $\mathrm{ICH}+\mathrm{EE}$ and sham groups spent significantly more time exploring the novel object than the old object and had significantly higher discrimination indices than did ICH mice exposed to the $\mathrm{SE}(72.55 \pm 8.80 \%$ vs. $34.55 \pm 9.70 \%, \mathrm{~F}=89.37, \mathrm{n}=7$ mice/group, $p<0.05$, Fig. $5 \mathrm{E}$ and $5 \mathrm{~F})$.

\section{EE increases the expression of Nrf2 and BDNF and inhibits glutaminase activity after ICH}

Western blot analysis revealed that EE exposure significantly increased Nrf2 and BDNF protein expression compared with standard environment (SE) exposure on day $28(F=10.58$ and 14.14 , respectively, $n=6$ mice/group, $p<0.05$, Figs.6A and 6B). Additionally, the expression of Nrf2 was significantly correlated 
with BDNF ( $\mathrm{R}^{2}=0.7732$, Fig.6C). Immunofluorescence staining (Fig. 6D) indicated that BDNF expression decreased after ICH+SE but was increased by exposure to an $E E(F=31.57, n=3-4$ mice/group, $p<0.05$, Fig. $6 \mathrm{E}$ ). Furthermore, the EE significantly inhibited glutaminase activity in brain tissue $(F=20.45$, Fig. $6 F)$ and striatal glutamate expression, as assessed by HPLC $(1.28 \pm 0.28 \mu \mathrm{g} / \mathrm{mL}$ vs. $2.58 \pm 0.70 \mu \mathrm{g} / \mathrm{mL}, \mathrm{F}=10.51$, Fig. $6 \mathrm{G})$ after $\mathrm{ICH}(\mathrm{n}=3 \mathrm{mice} / \mathrm{group}$, both $p<0.05)$.

\section{EE does not mitigate depression-like behaviors in $\mathrm{Nrf2} 2^{-/-}$mice with $\mathrm{ICH}$}

To determine whether EE mitigates depression-like behaviors through the Nrf2 signaling pathway, we first subjected $\mathrm{Nrf2}^{-/-}$mice to $\mathrm{ICH}$ and then exposed those mice to EE or SE and analyzed the immobility time in the TST 28 days after ICH. The immobility time did not differ between $\mathrm{Nrf}^{-/-} \mathrm{ICH}$ mice exposed to EE or $\mathrm{SE}(\mathrm{n}=8-10$ mice/group, $p>0.05)$, although the parameter is shorter in the WT mice exposed to the EE than those exposed to $\mathrm{SE}$ ( $\mathrm{n}=8-10$ mice/group, $p<0.05$, Fig. 7 ).

\section{Discussion}

In this study, we evaluated the benefits of EE on ICH-induced long-term functional outcomes. We showed that $\mathrm{EE}$ exposure did not affect the volume of the lesion or brain edema after ICH at $72 \mathrm{~h}$. However, EE exposure improved neurologic function and attenuated depression-and anxiety-like behaviors after ICH. In addition, it promoted spatial learning and memory. In particular, glutamate expression in the mouse striatum was increased after ICH but was reversed by exposure to EE. Furthermore, EE increased the protein expression of Nrf2 and BDNF and inhibited glutaminase activity in the ICH brain. However, EE did not mitigate depression-like behaviors in $\mathrm{Nrf2}^{-/}$mice with ICH (Fig. 8). These novel findings indicate that an $\mathrm{EE}$ improves long-term sensorimotor, emotion, and cognition after $\mathrm{ICH}$. The mechanisms underlie the EE stimulation may involve the Nrf2/BDNF/glutaminase pathway.

In this study, we used a collagenase-induced ICH model to produce acute cerebrovascular injury, similar to clinical ICH [41]. This model has a reproducible hematoma in the desired region of the brain. We evaluated tasks that can reflect the severity of PSD to improve the innovation of the project. We chose striatal ICH as the PSD model in our study because the incidence of depression in patients with $\mathrm{ICH}$ is closely related to the location of the hematoma $[42,43]$. Data also indicate that striatal hemorrhage causes severe damage to dopaminergic neurons [44], thereby inducing depression-like behavior in animals [45]. EE is a powerful tool to counteract cognitive and somatosensory deficits. Studies showed that the exposure of rats to EE has several beneficial effects in common with the administration of antidepressants [46]. Using the TST, SPT, and FST, we showed that the collagenase-induced striatal ICH model produced marked depression-like behavior in mice on day 28 . It is well known that increased immobility time in the TST and FST, reduced struggle to escape, or decreased sucrose intake can indicate a depressive state. We showed that EE exposure mitigated emotional dysfunction of ICH mice, as indicated by decreases in immobility time in the FST, increased struggling in the TST, and increased consumption of sweetened water. 
The pathogenesis of PSD is complex, and its neurobiological mechanisms differ from those of other depression subtypes. In mammals, Nrf2 upregulates antioxidant genes to help reduce inflammation and reactive oxygen species [47]. Nrf2 signaling decreases the production of proinflammatory cytokines and chemokine release factors [48], decreases the activity of MMP $2 / 9$, and reduces the production of other inflammatory mediators, for example, COX-2 and iNOS [49]. It also regulates the NF-KB and the MAPK pathways [50]. We reported the protective effect of Nrf2 after ICH in 2007[15]. Nrf2 is also involved in the antidepressant-like effects of agmatine [51]. We examined the expression of Nrf2 and its target gene BDNF by using Western blot analysis and immunofluorescence. We found that the Nrf2 level in the brain decreased after $\mathrm{ICH}$, a result similar to other reports. EE exposure encourages novel interactions with the environment and other social stimuli, stimulating the brain to release neural growth factors [52].

Depression is an incapacitating psychiatric disorder associated with decreased in monoamines and neurotrophic factors [53]. BDNF is known to regulate neurogenesis, synaptogenesis, and angiogenesis and promote neuronal survival [54]. It is also involved in the pathophysiology of depressive disorders. Its role in the effect of antidepressants began to be recognized years ago[55]. In our study, the expression level of BDNF in the perihematomal tissue decreased compared with that of the sham mice but reversed by an EE. Others have reported that serum BDNF levels are lower in patients with PSD than in healthy controls and, therefore, might predict the risk of PSD clinically[56, 57]. Previous studies showed that daily exposure to EE enhanced BDNF mRNA and protein expression levels and improved functional outcomes $[57,58]$. However, few studies addressed changes in brain BDNF levels in ICH patients or animal models of ICH-induced PSD. Heme oxygenase-1 (HO-1) and the BDNF-mediated pathway are involved in the pathophysiology of depression [59]. Several studies have demonstrated that the Nrf2 downstream molecule HO- 1 and its heme metabolites have significant anti-inflammatory effects $[59,60]$. Therefore, in our future study, we will take advantage of HO-1 knockout mice to investigate whether the $\mathrm{Nrf} 2 / \mathrm{HO}-1$ signaling pathway is involved in the PSD pathomechanism and whether EE exposure can activate it [61].

Glutamine-mediated oxidative stress may affect the extent of cell swelling and lead to other CNS diseases such as multiple sclerosis and brain edema[31, 62]. Glutaminase siRNA can protect against focal ischemia, suggesting that glutaminase may be a therapeutic target [63]. In patients with ICH, perihematomal glutamate levels increased, associated with increased brain water content [64]. In our study, we observed elevated glutamate levels in the hemorrhagic brain of mice by HPLC on day 28 , but exposure to EE returned glutamate to control levels. This result is consistent with previous studies, which showed that depression and poor neurologic outcomes are related to increased plasma glutamate concentrations after ICH [64-66]. Therefore, our data indicate that the Nrf2/BDNF/glutaminase pathway might be involved in EE-related improvement in PSD after ICH. Next, we subjected $\mathrm{Nrf2} 2^{-/-}$mice to ICH and determined whether EE mitigates PSD via the Nrf2 signaling pathway. We showed that the immobility time in TST did not differ significantly between the $\mathrm{Nrf2}^{-/-} \mathrm{ICH}$ mice exposed to EE or SE. This result suggests that EE does not mitigate depression-like behavior after ICH when Nrf2 is globally knocked out and further confirms the primary role of Nrf2 in EE exposure. 
An EE provides multiple sensorimotor stimuli and opportunities for training and learning, including social interaction, space exploration, and spontaneous physical activities[67, 68]. Similarly, EE improved learning skills and recognition ability in mice with $\mathrm{ICH}$ in our study. EE has also been shown to restore normal behavior by providing cytoskeletal restoration and synaptic changes in the hippocampus of rats exposed to an experimental model of depression [69].

Previous studies have demonstrated that EE can enhance brain plasticity after focal brain ischemic injury $[70,71]$. Here, we showed that daily exposure to EE after ICH had a beneficial effect on the motor function

of mice on days $3,5,7,14$, and 21 . This finding supports the results of previous studies on focal ischemia in rodents [71, 72], which indicates that EE stimulation can enhance lesion-induced plasticity during the first weeks and months of recovery after stroke[$[73,74]$.

In our study, ICH mice developed a very high incidence of depressive-like behaviors compared to control mice (about $53 \%$ vs. $2 \%$ ). Although PSD has been studied clinically for over a decade, an ideal PSD model to investigate the underlying pathomechanism is still lacking. Developing an appropriate PSD model is a pressing and challenging work in this young research field.

\section{Conclusions}

Taking together, we speculate that motor and emotional dysfunction after $\mathrm{ICH}$ is due to an imbalance of neurotransmitters and neurobiological changes and that an EE could promote functional recovery by reducing oxidative damage. In conclusion, we demonstrated that EE exposure improves sensorimotor function, depression- and anxiety-like behaviors, and cognitive function after $\mathrm{ICH}$. The underlying mechanisms may involve the Nrf2/BDNF/glutaminase pathway. Thus, the provision of EE might be a potential therapeutic strategy to treat post-ICH depression.

\section{Abbreviations}

BDNF, brain-derived neurotrophic factor; EE, enriched environment; EPM, elevated plus-maze; FST, forced swim test; HPLC, high-performance liquid chromatography; $\mathrm{ICH}$, intracerebral hemorrhage; MWM, Morris water maze; Nrf2, nuclear factor erythroid 2-related factor 2; PSD, post-stroke depression; SE, standard environment; SPT, sucrose preference test; TST, tail suspension test.

\section{Declarations}

\section{Consent for publication}

Not applicable.

\section{Competing interests}

The authors declare that they have no competing or conficting interests. 
Availability of data and materials

The authors confirm that all data underlying the findings are fully available without restriction. All relevant data are within the paper and its supporting information files.

\section{Funding}

This work was partially supported by Henan Joint Funds with the National Natural Science Foundation of China (No. U1704166 to XC), The Key Project of Science and Technology of department of Science and Technology of Henan Province (grant number 212102310220 to XC),

\section{Author contribution}

Xuemei Chen, Weidong Zang and Jian Wang conceived the study. Xuemei Chen and Peijun Jia performed the experiments and analyzed data. Peijun Jia and Jian Wang wrote and revised the manuscript. Junmin Wang, Xiuhua Ren and Yinpei Xing performed molecular experiments. Danyang Chen, Xinling Zhang, Siqi Zhou, Xi Liu, Shangchen Yu, Shaoshuai Wang, Zefu Li and Chao Jiang performed animal behavior tests or analyzed data. All the co-authors commented, edited, and critically revised the manuscript.

\section{Ethics approval and consent to participate}

Human subjects or samples were not used in this study. All animal experiments were approved by the Institutional Animal Care and Use Committee of Zhengzhou University.

\section{References}

1. Villa RF, Ferrari F, Moretti A: Post-stroke depression: Mechanisms and pharmacological treatment. Pharmacol Ther 2018, 184:131-144.

2. Robinson RG, Jorge RE: Post-Stroke Depression: A Review. Am J Psychiatry 2016, 173:221-231.

3. Feng P, Huang C: Phospholipase D-mTOR signaling is compromised in a rat model of depression. $J$ Psychiatr Res 2013, 47:579-585.

4. Feng C, Fang M, Liu XY: The neurobiological pathogenesis of poststroke depression. ScientificWorldJournal 2014, 2014:521349.

5. Bartoli F, Di Brita C, Crocamo C, Clerici M, Carra G: Early Post-stroke Depression and Mortality: MetaAnalysis and Meta-Regression. Front Psychiatry 2018, 9:530.

6. Kronenberg G, Gertz K, Heinz A, Endres M: Of mice and men: modelling post-stroke depression experimentally. Br J Pharmacol 2014, 171:4673-4689.

7. Ren H, Han R, Chen X, Liu X, Wan J, Wang L, Yang X, Wang J: Potential therapeutic targets for intracerebral hemorrhage-associated inflammation: An update. J Cereb Blood Flow Metab 2020, 40:1752-1768. 
8. Zhang Y, Xu D, Qi H, Yuan Y, Liu H, Yao S, Yuan S, Zhang J: Enriched environment promotes poststroke neurogenesis through NF-kappaB-mediated secretion of IL-17A from astrocytes. Brain Res 2018, 1687:20-31.

9. Johansson BB, Ohlsson AL: Environment, social interaction, and physical activity as determinants of functional outcome after cerebral infarction in the rat. Exp Neurol 1996, 139:322-327.

10. Paban V, Chambon C, Manrique C, Touzet C, Alescio-Lautier B: Neurotrophic signaling molecules associated with cholinergic damage in young and aged rats: environmental enrichment as potential therapeutic agent. Neurobiol Aging 2011, 32:470-485.

11. Loubinoux I, Kronenberg G, Endres M, Schumann-Bard P, Freret T, Filipkowski RK, Kaczmarek L, PopaWagner A: Post-stroke depression: mechanisms, translation and therapy. J Cell Mol Med 2012, 16:1961-1969.

12. Strekalova T, Evans M, Costa-Nunes J, Bachurin S, Yeritsyan N, Couch Y, Steinbusch HM, Eleonore Kohler S, Lesch KP, Anthony DC: TIr4 upregulation in the brain accompanies depression- and anxietylike behaviors induced by a high-cholesterol diet. Brain Behav Immun 2015, 48:42-47.

13. Audet MC, Anisman H: Interplay between pro-inflammatory cytokines and growth factors in depressive illnesses. Front Cell Neurosci 2013, 7:68.

14. Maes M, Fisar Z, Medina M, Scapagnini G, Nowak G, Berk M: New drug targets in depression: inflammatory, cell-mediated immune, oxidative and nitrosative stress, mitochondrial, antioxidant, and neuroprogressive pathways. And new drug candidates--Nrf2 activators and GSK-3 inhibitors. Inflammopharmacology 2012, 20:127-150.

15. Wang J, Fields J, Zhao C, Langer J, Thimmulappa RK, Kensler TW, Yamamoto M, Biswal S, Dore S: Role of Nrf2 in protection against intracerebral hemorrhage injury in mice. Free Radic Biol Med 2007, 43:408-414.

16. Ren H, Han R, Liu X, Wang L, Koehler RC, Wang J: Nrf2-BDNF-TrkB pathway contributes to cortical hemorrhage-induced depression, but not sex differences. J Cereb Blood Flow Metab 2021, 8.

17. Mendez-David I, Tritschler L, Ali ZE, Damiens MH, Pallardy M, David DJ, Kerdine-Romer S, Gardier AM: Nrf2-signaling and BDNF: A new target for the antidepressant-like activity of chronic fluoxetine treatment in a mouse model of anxiety/depression. Neurosci Lett 2015, 597:121-126.

18. Zhu X, Nedelcovych MT, Thomas AG, Hasegawa Y, Moreno-Megui A, Coomer W, Vohra V, Saito A, Perez G, Wu Y, et al: JHU-083 selectively blocks glutaminase activity in brain CD11b(+) cells and prevents depression-associated behaviors induced by chronic social defeat stress. Neuropsychopharmacology 2019, 44:683-694.

19. Maezawa I, Jin LW: Rett syndrome microglia damage dendrites and synapses by the elevated release of glutamate. J Neurosci 2010, 30:5346-5356.

20. Han X, Lan X, Li Q, Gao Y, Zhu W, Cheng T, Maruyama T, Wang J: Inhibition of prostaglandin E2 receptor EP3 mitigates thrombin-induced brain injury. J Cereb Blood Flow Metab 2016, 36:10591074. 
21. Chang CF, Cho S, Wang J: (-)-Epicatechin protects hemorrhagic brain via synergistic Nrf2 pathways. Ann Clin Transl Neurol 2014, 1:258-271.

22. Zhao X, Wu T, Chang CF, Wu H, Han X, Li Q, Gao Y, Hou Z, Maruyama T, Zhang J, Wang J: Toxic role of prostaglandin E2 receptor EP1 after intracerebral hemorrhage in mice. Brain Behav Immun 2015, 46:293-310.

23. Li Q, Han X, Lan X, Gao Y, Wan J, Durham F, Cheng T, Yang J, Wang Z, Jiang C, et al: Inhibition of neuronal ferroptosis protects hemorrhagic brain. JCI Insight 2017, 2:e90777.

24. Vrinda M, Sasidharan A, Aparna S, Srikumar BN, Kutty BM, Shankaranarayana Rao BS: Enriched environment attenuates behavioral seizures and depression in chronic temporal lobe epilepsy. Epilepsia 2017, 58:1148-1158.

25. Slater AM, Cao L: A Protocol for Housing Mice in an Enriched Environment. J Vis Exp 2015:e52874.

26. Li Q, Wan J, Lan X, Han X, Wang Z, Wang J: Neuroprotection of brain-permeable iron chelator VK-28 against intracerebral hemorrhage in mice. J Cereb Blood Flow Metab 2017, 37:3110-3123.

27. Sánchez-Román J, Varela-Aguilar JM, Bravo-Ferrer J, Sequeiros Madueño E, Fernández de Bobadilla M: Idiopathic orbital myositis: treatment with cyclosporin. Ann Rheum Dis. 1993 Jan,52(1):84-5. doi: 10.1136/ard.52.1.84-b.

28. Jia P, He J, Li Z, Wang J, Jia L, Hao R, Lai J, Zang W, Chen X: Profiling of Blood-Brain Barrier Disruption in Mouse Intracerebral Hemorrhage Models: Collagenase Injection vs. Autologous Arterial Whole Blood Infusion. Front Cell Neurosci 2021, 15.

29. Shi X, Bai H, Wang J, Huang L, He M, Zheng X, Duan Z, Chen D, Zhang J, Chen X: Behavioral Assessment of Sensory, Motor, Emotion, and Cognition in Rodent Models of Intracerebral Hemorrhage. Front Neurol 2021, 12.

30. Wang J, Jiang C, Zhang K, Lan X, Chen X, Zang W, Wang Z, Guan F, Zhu C, Yang X, Lu H: Melatonin receptor activation provides cerebral protection after traumatic brain injury by mitigating oxidative stress and inflammation via the Nrf2 signaling pathway. Free Radic Biol Med 2019, 131:345-355.

31. Zhu W, Gao Y, Wan J, Lan X, Han X, Zhu S, Zang W, Chen X, Ziai W, Hanley DF, et al: Changes in motor function, cognition, and emotion-related behavior after right hemispheric intracerebral hemorrhage in various brain regions of mouse. Brain Behav Immun 2018, 69:568-581.

32. Carlson GC, Lin RE, Chen Y, Brookshire BR, White RS, Lucki I, Siegel SJ, Kim SF: Dexras1 a unique rasGTPase interacts with NMDA receptor activity and provides a novel dissociation between anxiety, working memory and sensory gating. Neuroscience 2016, 322:408-415.

33. Can A, Dao DT, Terrillion CE, Piantadosi SC, Bhat S, Gould TD: The tail suspension test. J Vis Exp 2012:e3769.

34. Hirata N, Hattori S, Shoji H, Funakoshi H, Miyakawa T: Comprehensive behavioral analysis of indoleamine 2,3-dioxygenase knockout mice. Neuropsychopharmacol Rep 2018, 38:133-144.

35. Dong MX, Li CM, Shen P, Hu QC, Wei YD, Ren YF, Yu J, Gui SW, Liu YY, Pan JX, Xie P: Recombinant tissue plasminogen activator induces long-term anxiety-like behaviors via the ERK1/2-GAD1-GABA cascade in the hippocampus of a rat model. Neuropharmacology 2018, 128:119-131. 
36. Zhang R, Wang J, Huang L, Wang TJ, Huang Y, Li Z, He J, Sun C, Chen X: The pros and cons of motor, memory, and emotion-related behavioral tests in the mouse traumatic brain injury model. Neurol Res 2021, 26:1-25.

37. Bacchi AD, Ponte B, Vieira ML, de Paula JC, Mesquita SF, Gerardin DC, Moreira EG: Developmental exposure to Passiflora incarnata induces behavioural alterations in the male progeny. Reprod Fertil Dev 2013, 25:782-789.

38. Lan X, Han X, Li Q, Wang J: (-)-Epicatechin, a Natural Flavonoid Compound, Protects Astrocytes Against Hemoglobin Toxicity via Nrf2 and AP-1 Signaling Pathways. Mol Neurobio/ 2017, 54:78987907.

39. Wu T, Wu H, Wang J, Wang J: Expression and cellular localization of cyclooxygenases and prostaglandin E synthases in the hemorrhagic brain. J Neuroinflammation 2011, 8:22.

40. Wang F, Wan P, Wang W, Xiao B, Jin H, Jin Q: Dopamine in the hippocampal dentate gyrus modulates spatial learning via D1-like receptors. Brain Res Bull 2019, 144:101-107.

41. Wang J, Dore S: Inflammation after intracerebral hemorrhage. J Cereb Blood Flow Metab 2007, 27:894-908.

42. Stern-Nezer S, Eyngorn I, Mlynash M, Snider RW, Venkatsubramanian C, Wijman CAC, Buckwalter MS: Depression one year after hemorrhagic stroke is associated with late worsening of outcomes. NeuroRehabilitation 2017, 41:179-187.

43. Christensen MC, Mayer SA, Ferran JM, Kissela B: Depressed mood after intracerebral hemorrhage: the FAST trial. Cerebrovasc Dis 2009, 27:353-360.

44. Yang Y, Zhang K, Zhong J, Wang J, Yu Z, Lei X, Chen X, Quan Y, Xian J, Chen Y, et al: Stably maintained microtubules protect dopamine neurons and alleviate depression-like behavior after intracerebral hemorrhage. Sci Rep 2018, 8:12647.

45. Zhu W, Gao Y, Chang CF, Wan JR, Zhu SS, Wang J: Mouse models of intracerebral hemorrhage in ventricle, cortex, and hippocampus by injections of autologous blood or collagenase. PLOS One 2014, 9 .

46. Ickes BR, Pham TM, Sanders LA, Albeck DS, Mohammed AH, Granholm AC: Long-term environmental enrichment leads to regional increases in neurotrophin levels in rat brain. Exp Neuro/ 2000, 164:4552.

47. Bakunina N, Pariante CM, Zunszain PA: Immune mechanisms linked to depression via oxidative stress and neuroprogression. Immunology 2015, 144:365-373.

48. Kobayashi EH, Suzuki T, Funayama R, Nagashima T, Hayashi M, Sekine H, Tanaka N, Moriguchi T, Motohashi H, Nakayama K, Yamamoto M: Nrf2 suppresses macrophage inflammatory response by blocking proinflammatory cytokine transcription. Nat Commun 2016, 7:11624.

49. Benedict AL, Mountney A, Hurtado A, Bryan KE, Schnaar RL, Dinkova-Kostova AT, Talalay P: Neuroprotective effects of sulforaphane after contusive spinal cord injury. J Neurotrauma 2012, 29:2576-2586. 
50. Ahmed SM, Luo L, Namani A, Wang XJ, Tang X: Nrf2 signaling pathway: Pivotal roles in inflammation. Biochim Biophys Acta Mol Basis Dis 2017, 1863:585-597.

51. Freitas AE, Egea J, Buendia I, Gomez-Rangel V, Parada E, Navarro E, Casas Al, Wojnicz A, Ortiz JA, Cuadrado A, et al: Agmatine, by Improving Neuroplasticity Markers and Inducing Nrf2, Prevents Corticosterone-Induced Depressive-Like Behavior in Mice. Mol Neurobiol 2016, 53:3030-3045.

52. Wang L, Cao M, Pu T, Huang H, Marshall C, Xiao M: Enriched Physical Environment Attenuates Spatial and Social Memory Impairments of Aged Socially Isolated Mice. Int J Neuropsychopharmacol 2018, 21:1114-1127.

53. Duman RS: Role of neurotrophic factors in the etiology and treatment of mood disorders. Neuromolecular Med 2004, 5:11-25.

54. Miao H, Li R, Han C, Lu X, Zhang H: Minocycline promotes posthemorrhagic neurogenesis via M2 microglia polarization via upregulation of the TrkB/BDNF pathway in rats. J Neurophysio/2018, 120:1307-1317.

55. Shirayama Y, Chen AC, Nakagawa S, Russell DS, Duman RS: Brain-derived neurotrophic factor produces antidepressant effects in behavioral models of depression. J Neurosci 2002, 22:3251-3261.

56. Li J, Zhao YD, Zeng JW, Chen XY, Wang RD, Cheng SY: Serum Brain-derived neurotrophic factor levels in post-stroke depression. J Affect Disord 2014, 168:373-379.

57. Zhao LR, Risedal A, Wojcik A, Hejzlar J, Johansson BB, Kokaia Z: Enriched environment influences brain-derived neurotrophic factor levels in rat forebrain after focal stroke. Neurosci Lett 2001, 305:169-172.

58. Dahlqvist P, Ronnback A, Risedal A, Nergardh R, Johansson IM, Seckl JR, Johansson BB, Olsson T: Effects of postischemic environment on transcription factor and serotonin receptor expression after permanent focal cortical ischemia in rats. Neuroscience 2003, 119:643-652.

59. Manosso LM, Moretti M, Rosa JM, Cunha MP, Rodrigues ALS: Evidence for the involvement of heme oxygenase-1 in the antidepressant-like effect of zinc. Pharmacol Rep 2017, 69:497-503.

60. Chen-Roetling J, Regan RF: Targeting the Nrf2-Heme Oxygenase-1 Axis after Intracerebral Hemorrhage. Curr Pharm Des 2017, 23:2226-2237.

61. Wang J, Doré S: Heme oxygenase-1 exacerbates early brain injury after intracerebral haemorrhage. Brain 2007, 130:1643-1652.

62. Jayakumar AR, Rao KV, Murthy Ch R, Norenberg MD: Glutamine in the mechanism of ammoniainduced astrocyte swelling. Neurochem Int 2006, 48:623-628.

63. Thomas AG, O'Driscoll CM, Bressler J, Kaufmann W, Rojas CJ, Slusher BS: Small molecule glutaminase inhibitors block glutamate release from stimulated microglia. Biochem Biophys Res Commun 2014, 443:32-36.

64. Wu G, Li S, Wang L, Mao Y: The perihematomal glutamate level is associated with the outcome of patients with basal ganglia hematomas treated by minimally invasive procedures. Neurol Res 2013, 35:829-836. 
65. Castillo J, Davalos A, Alvarez-Sabin J, Pumar JM, Leira R, Silva Y, Montaner J, Kase CS: Molecular signatures of brain injury after intracerebral hemorrhage. Neurology 2002, 58:624-629.

66. McCarthy DJ, Alexander R, Smith MA, Pathak S, Kanes S, Lee CM, Sanacora G: Glutamate-based depression GBD. Med Hypotheses 2012, 78:675-681.

67. Yang Y, Zhang M, Kang X, Jiang C, Zhang H, Wang P, Li J: Impaired adult hippocampal neurogenesis and cognitive ability in a mouse model of intrastriatal hemorrhage. Neurosci Lett 2015, 599:133-139.

68. Fan D, Li J, Zheng B, Hua L, Zuo Z: Enriched Environment Attenuates Surgery-Induced Impairment of Learning, Memory, and Neurogenesis Possibly by Preserving BDNF Expression. Mol Neurobio/2016, 53:344-354.

69. Sifonios L, Trinchero M, Cereseto M, Ferrero A, Cladouchos ML, Macedo GF, Reines A, Wikinski S: An enriched environment restores normal behavior while providing cytoskeletal restoration and synaptic changes in the hippocampus of rats exposed to an experimental model of depression. Neuroscience 2009, 164:929-940.

70. Nudo RJ, Wise BM, SiFuentes F, Milliken GW: Neural substrates for the effects of rehabilitative training on motor recovery after ischemic infarct. Science 1996, 272:1791-1794.

71. Ohlsson AL, Johansson BB: Environment influences functional outcome of cerebral infarction in rats. Stroke 1995, 26:644-649.

72. Nygren J, Wieloch T: Enriched environment enhances recovery of motor function after focal ischemia in mice, and downregulates the transcription factor NGFI-A. J Cereb Blood Flow Metab 2005, 25:1625-1633.

73. Witte OW: Lesion-induced plasticity as a potential mechanism for recovery and rehabilitative training. Curr Opin Neurol 1998, 11:655-662.

74. Kreisel SH, Bazner H, Hennerici MG: Pathophysiology of stroke rehabilitation: temporal aspects of neuro-functional recovery. Cerebrovasc Dis 2006, 21:6-17.

\section{Figures}




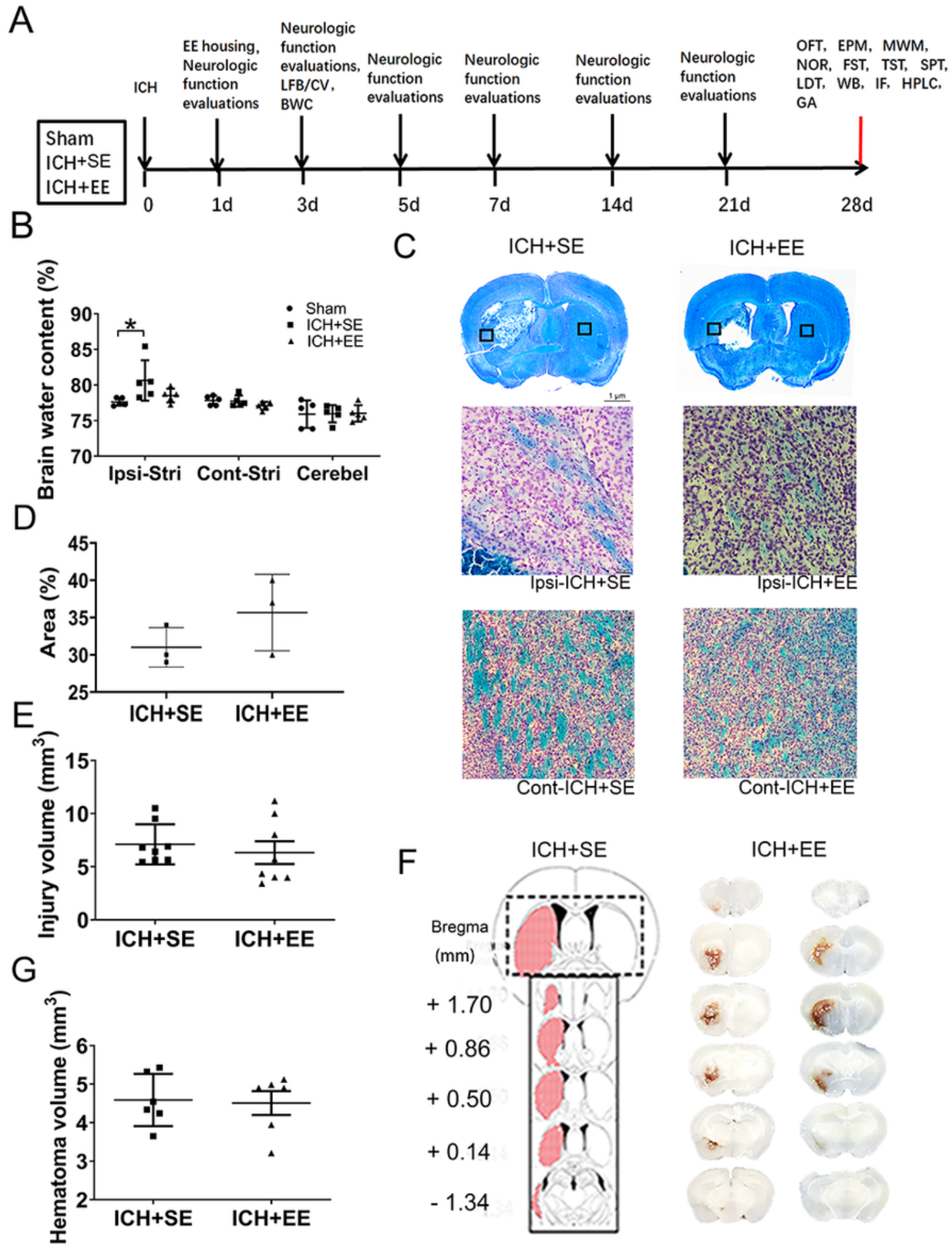

\section{Figure 1}

Enriched environment (EE) has no effect on acute brain injury after ICH (A) Experimental design. The timeline shows the sequence of all behavioral tests and experimental procedures, beginning on the day of surgery (day 0). LFB, Luxol fast blue, CV, Cresyl violet, BWC, Brain water content, OFT, open field test, EPM, elevated plus maze, MWM, Morris water maze, NOR, novel object recognition, FST, forced swim test, TST, tail suspension test, SPT, sucrose preference test, LDT, light/dark transition test, WB, Western blot, IF, 
immunofluorescence, HPLC, high-performance liquid chromatography, GA, glutaminase activity. (B) On day 3 after $\mathrm{ICH}$, mice exposed to an $\mathrm{EE}$ did not reduce brain water content in the ipsilateral hemisphere, compared to mice that received ICH and standard conditions (ICH+SE). $\mathrm{n}=5$ mice/group. $p>0.05$ vs. sham group (one-way ANOVA followed by the Bonferroni post hoc test). Cont-Stri, contralateral striatum, Ipsi-Stri, ipsilateral striatum, Cerebel, cerebellum. (C) Top: Representative Luxol fast blue/Cresyl violetstained brain sections from ICH+SE and ICH+EE groups (scale bar $=1 \mathrm{~mm}$ ). Bottom: High magnification of the dashed areas in the top photograph on the ipsilateral side (Scale bar $=50 \mu \mathrm{m}$ ). (D) Left: Schematic illustration of the spatial extent of the hemorrhagic lesion $72 \mathrm{~h}$ after microinjection of collagenase VII into the left striatum. Right: Representative fresh brain sections show hematomas (red areas) in mice exposed to standard conditions or EE. (E) Quantification analysis did not show differences in the volume of brain injury between the $\mathrm{ICH}+\mathrm{SE}$ and $\mathrm{ICH}+\mathrm{EE}$ groups. $\mathrm{n}=8$ mice/group (t test). $(F)$ The plots graph shows that EE did not increase the percentage of areas with normal myelin after $\mathrm{ICH}$ on day $3 . \mathrm{n}=3$ mice/group $(t$ test). (G) Quantification analysis showed no difference in hematoma volume between the ICH+SE and $\mathrm{ICH}+\mathrm{EE}$ groups. $\mathrm{n}=6$ mice/group ( $t$ test). Data are expressed as mean $\pm \mathrm{SD}$.

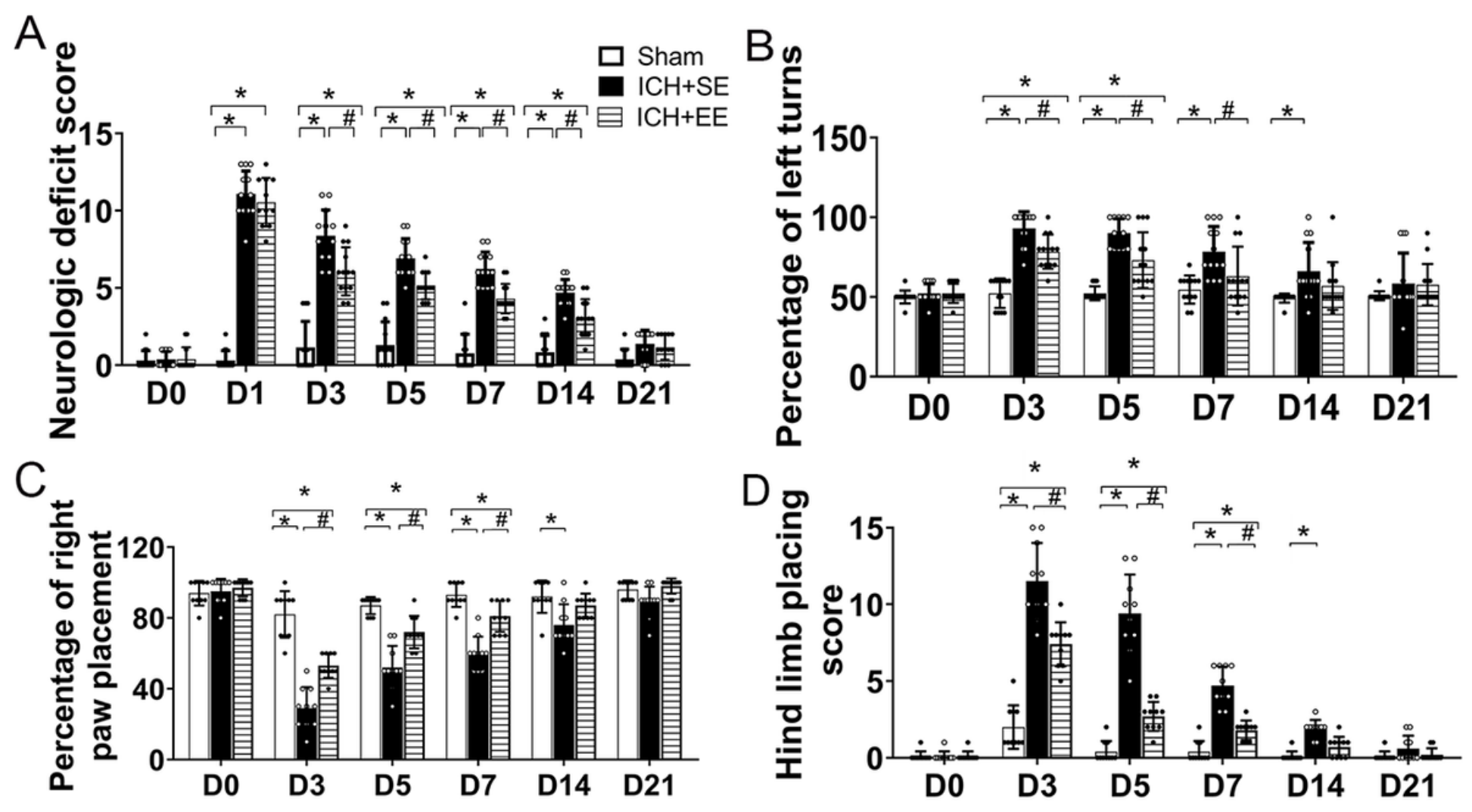

Figure 2

After $\mathrm{ICH}$, the enriched environment (EE) mitigates neurologic deficits and motor dysfunction. (A) Housing in an EE decreased the neurologic deficit scores of mice on days $1,3,5,7$, and 14 after ICH. $n=10-13$ mice/group. ${ }^{*} p<0.05$ vs. sham group, ${ }^{\#} p<0.05$ vs. ICH group (repeated measures ANOVA followed by the Bonferroni post hoc test). (B) ICH mice exposed to EE performed better in the corner turn test than ICH mice exposed to the standard environment (SE) on days 3, 5, and 7 after ICH. $\mathrm{n}=13$ mice/group. ${ }^{*} p<$ 
0.05 vs. sham group, ${ }^{\#} p<0.05$ vs. ICH+SE group (repeated measures ANOVA followed by the Bonferroni post hoc test). (C) ICH mice exposed to EE had a better motor performance in the hind-limb placement test than ICH mice exposed to SE on days 3, 5, and 7. $n=10$ mice/group. ${ }^{*} p<0.05$ vs. sham group, ${ }^{*} p<$ $0.05 \mathrm{vs}$. ICH+SE group (repeated measures ANOVA followed by the Bonferroni post hoc test). Values are mean $\pm S D$.

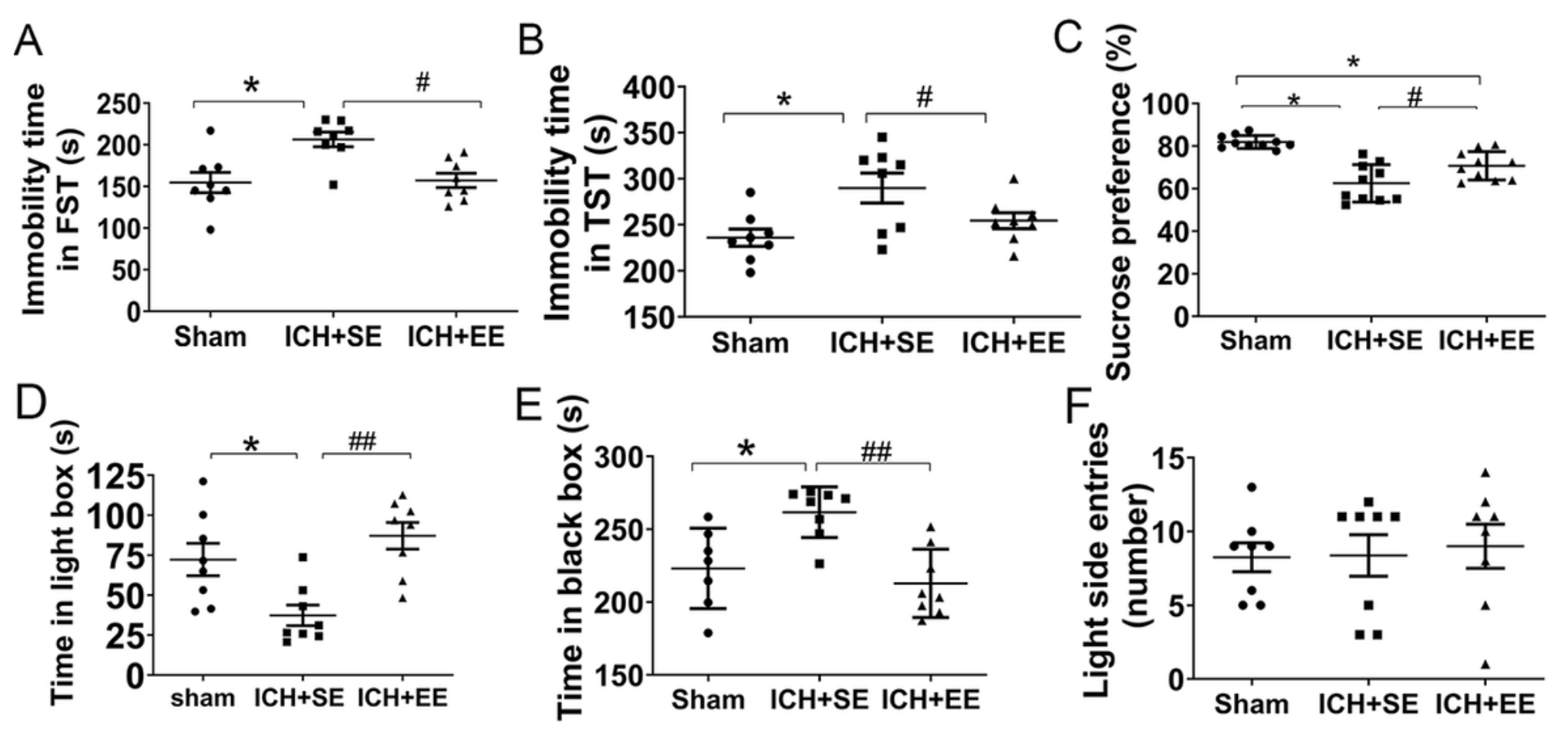

Figure 3

The Enriched environment (EE) mitigates depression-like behaviors in mice after ICH. (A and B) Mice in the ICH+EE group exhibited less immobility time in the forced swim test (FST, A) and tail suspension test (TST, B) on day 28 than ICH mice housed in a standard environment (SE). $\mathrm{n}=8$ mice/group. $\mathrm{F}=7.47$, 5.28 , respectively, ${ }^{*} p<0.05,{ }^{*} p<0.01$ vs. sham group, ${ }^{*} p<0.05$ vs. ICH group (one-way ANOVA followed by the Bonferroni post hoc test). (C) Mice in the ICH+EE group consumed more sucrose-sweetened water in the sucrose preference test than ICH mice in the standard environment on day $28 . n=10$ mice/group. $\mathrm{F}=21.85,{ }^{*} p<0.05$ vs. sham group, ${ }^{*} p<0.05$ vs. ICH group (one-way ANOVA followed by the Bonferroni post hoc test). (D and $E$ ) In the light/dark transition test, the mice in the $\mathrm{ICH}+\mathrm{EE}$ group spent more time in the light-box (D) and less time in the dark box (E) than those in the ICH group. $n=8$ mice/group. $F=8.954$, $8.954,{ }^{*} p<0.05$ vs. sham group, ${ }^{\# \#} p<0.01$ vs. ICH group (one-way ANOVA followed by the Bonferroni post hoc test). (F) The number of entries in the light-box was not statistically different between the ICH and $\mathrm{ICH}+\mathrm{EE}$ groups. $\mathrm{n}=8$ mice/group. $\mathrm{F}=0.09439$, values are mean \pm SD. 
A
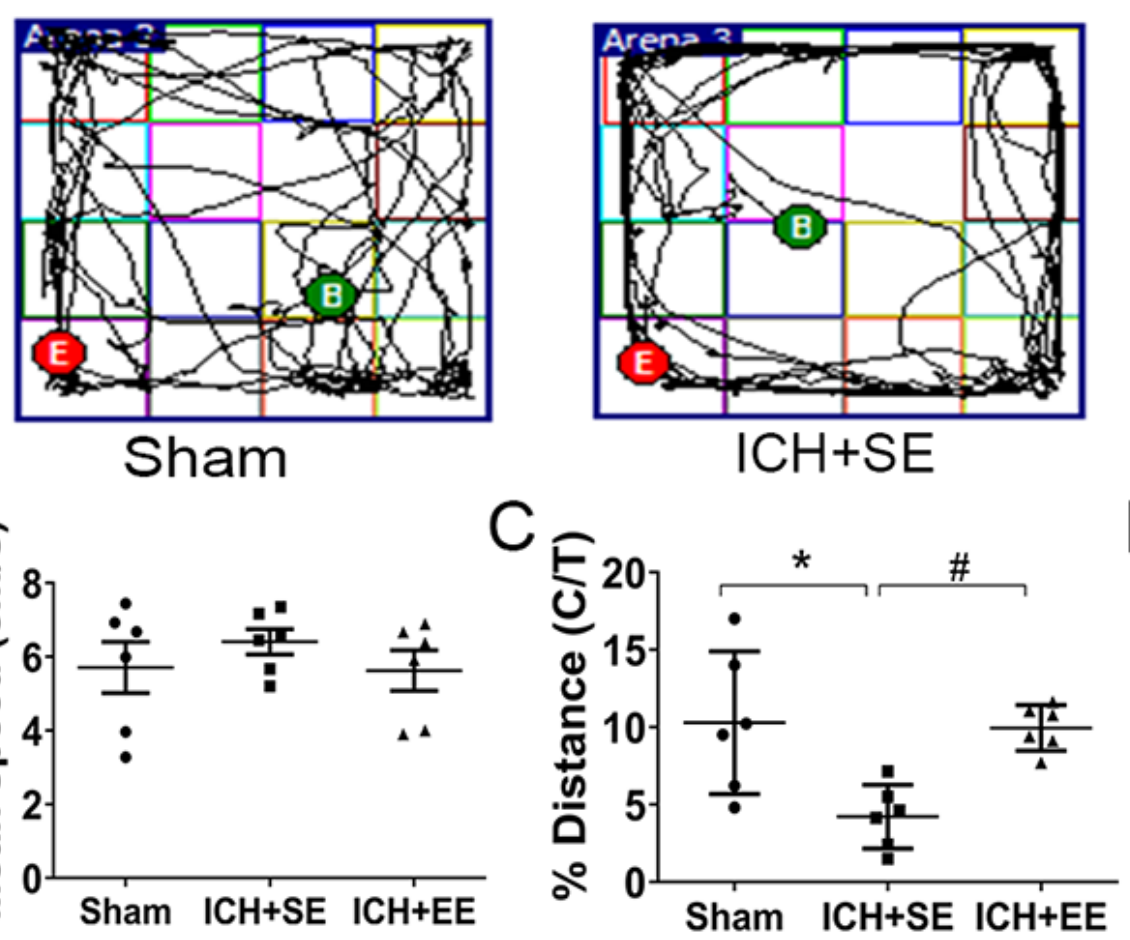

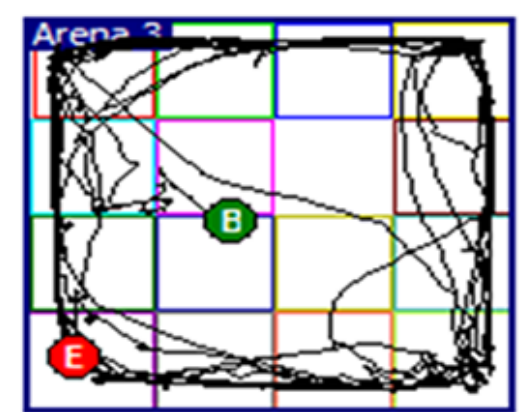

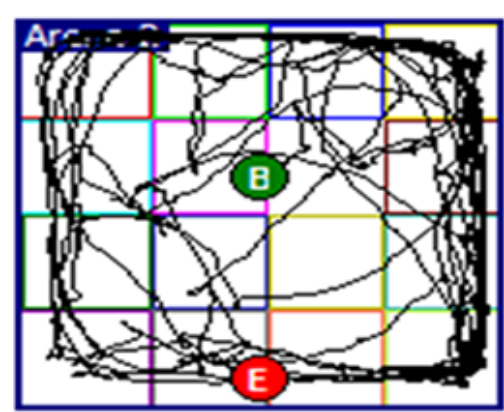

$\mathrm{ICH}+\mathrm{EE}$
Sham

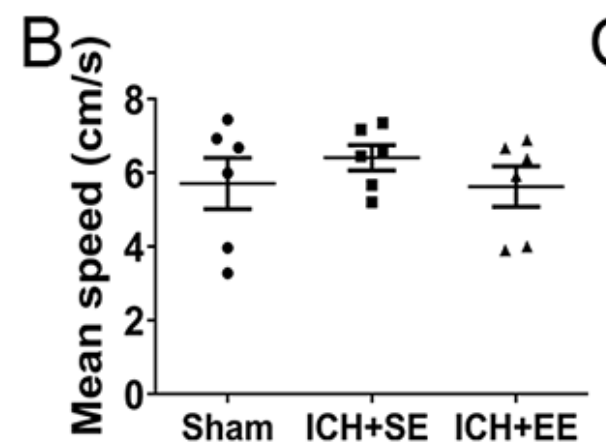

C

$\mathrm{ICH}+\mathrm{SE}$

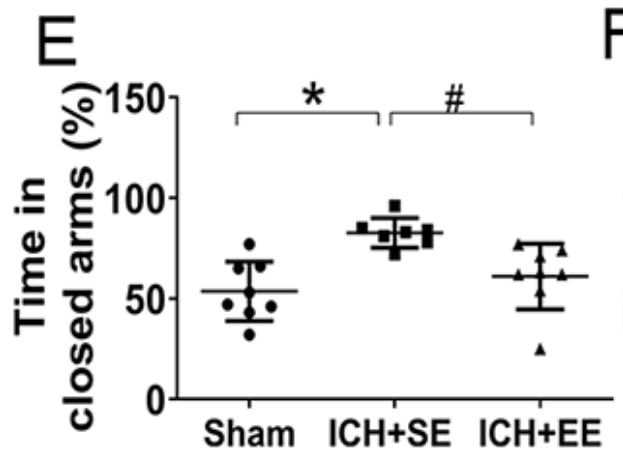

$\mathrm{D}$

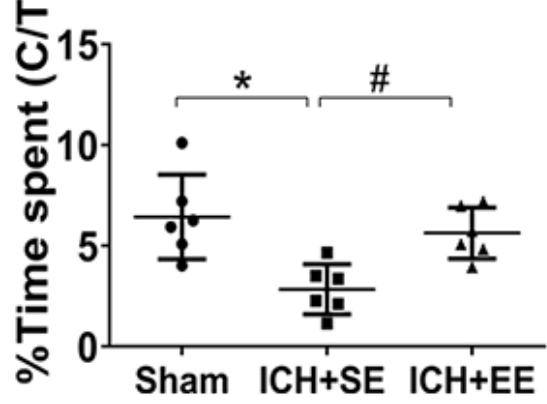

F

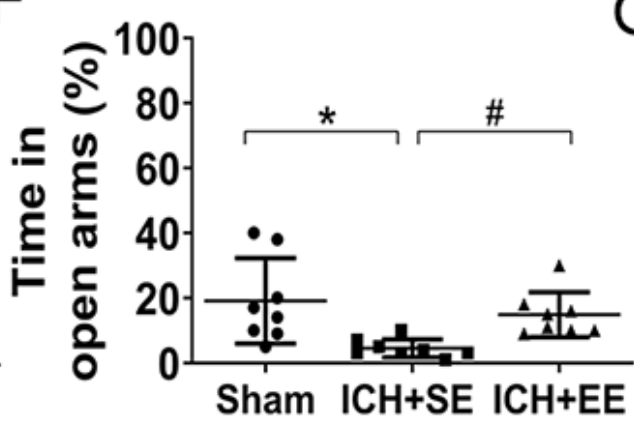

$G$

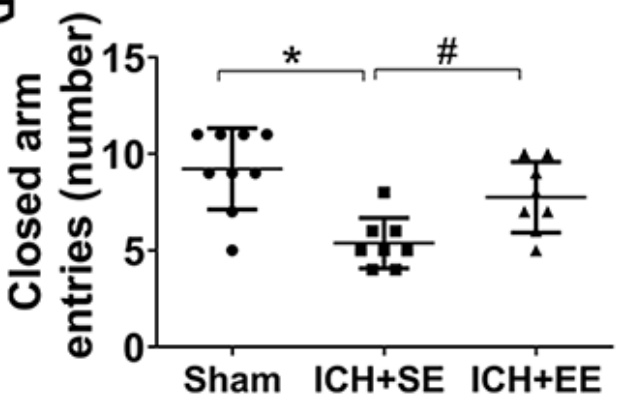

Figure 4

An enriched environment (EE) mitigates anxiety-like behaviors in mice after ICH. (A) Trajectories of mice from the three groups in the open field test on day 28. B, Begin, E, End. (B) The mean speeds of mice did not differ in the open field test. $n=6$ mice/group. ( $C$ and $\mathbf{D}$ ) Mice in the ICH+EE group traveled a significantly longer distance in the center area of the open field (C) and spent more time in the open field (D) than $\mathrm{ICH}$ mice exposed to the standard environment (ICH+SE) group. $\mathrm{C} / \mathrm{T}$, center area/total area, $\mathrm{n}=6$ mice/group. $\mathrm{F}=1.33,7.57$, respectively, ${ }^{\star \star} p<0.01$ vs. sham group, ${ }^{\#} p<0.05 \mathrm{vs}$. ICH+SE group (one-way ANOVA followed by the Bonferroni post hoc test). (E-G) In the elevated plus-maze test, mice in the ICH+EE group spent more time in open arms (E) and less time in closed arms than those in the ICH+SE group (F). (G) Furthermore, they entered the closed arms more times than did mice in the ICH+SE group. $\mathrm{n}=7-9$ mice/group. $\mathrm{F}=5.93,9.10$, and 9.81 , respectively, ${ }^{\star} p<0.05,{ }^{*} p<0.01$ vs. sham group, ${ }^{\#} p<0.05$ vs. ICH+SE group (one-way ANOVA followed by the Bonferroni post hoc test). Values are mean \pm SD. 


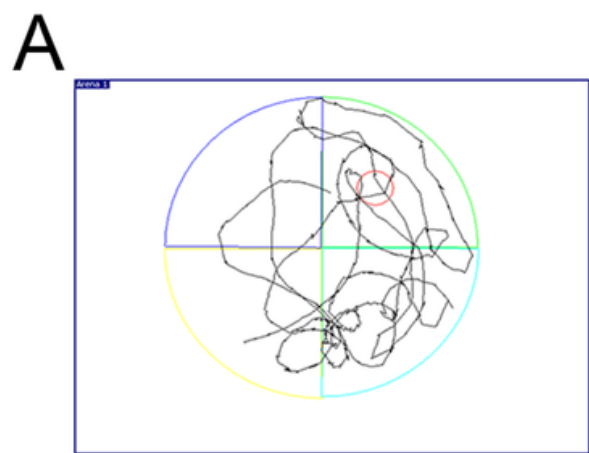

Sham

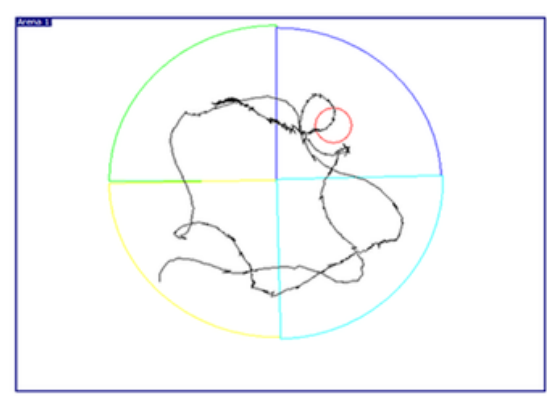

$\mathrm{ICH}+\mathrm{SE}$

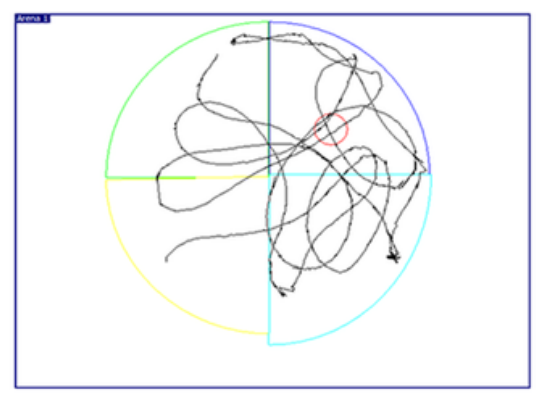

$\mathrm{ICH}+\mathrm{EE}$

$\mathrm{B}$
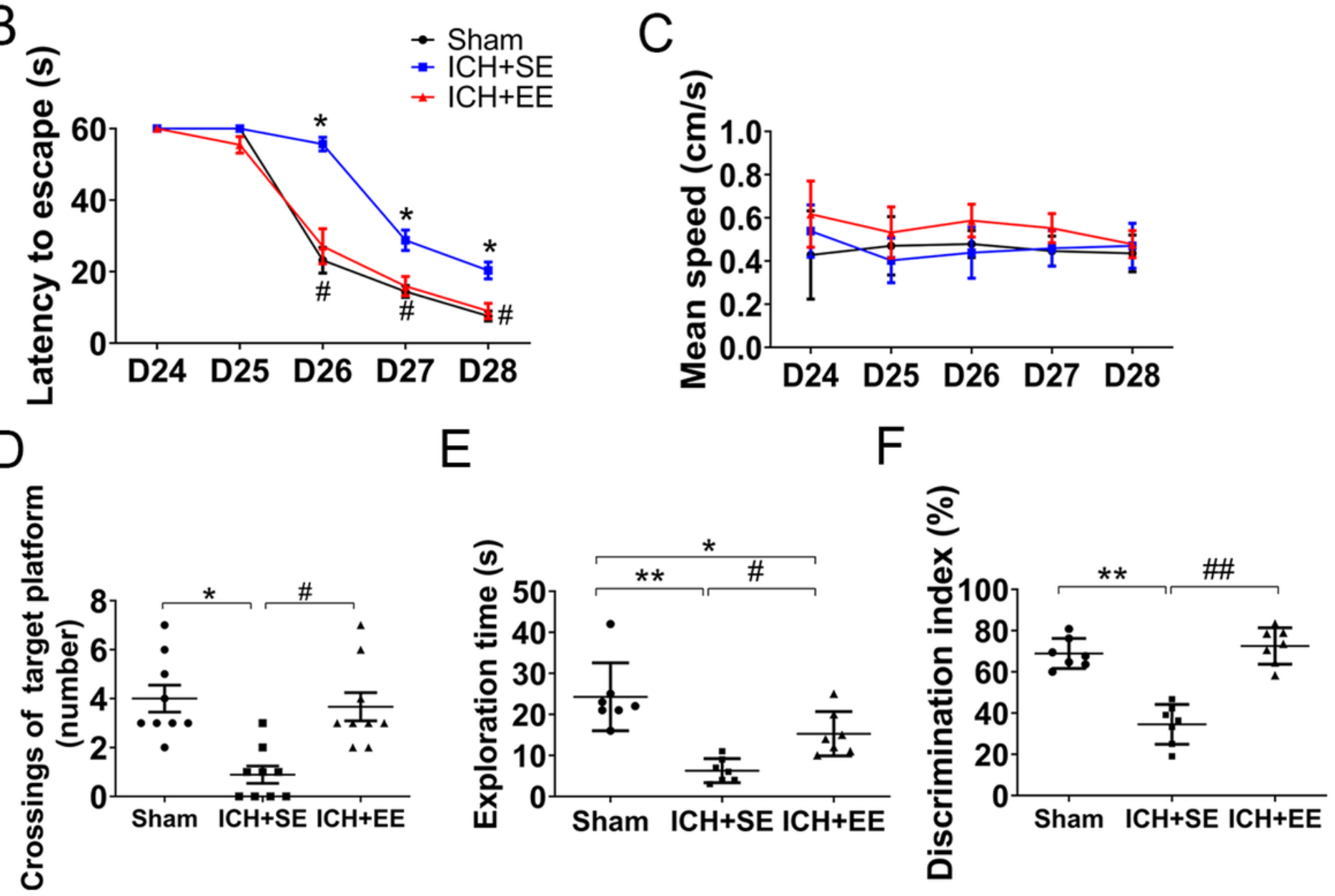

Figure 5

An enriched environment (EE) improves spatial learning and memory function after ICH. (A) Swimming trajectories of mice from each group in the Morris water maze (MWM) test on day 28. (B) In the MWM test, EE exposure decreased escape latency on days 26,27 , and 28 compared to standard environment (SE) exposure, $\mathrm{n}=9-10$ mice/group, ${ }^{*} p<0.05$ vs. sham group, ${ }^{\#} p<0.05$ vs. ICH+SE group (repeated measures ANOVA followed by the Bonferroni post hoc test). (C) Exposure to EE did not affect the mean swim speed of mice in the MWM test on days $25,26,27$, or 28. $P>0.05$ vs. The ICH+SE group (repeatedmeasures ANOVA followed by the Bonferroni post hoc test, $F=1.373$ ). (D) Mice from the ICH+EE group 
crossed the target platform more times than mice from the ICH+SE group on day $28 . \mathrm{n}=9$ mice/group. * $p$ $<0.05$ vs. sham group, ${ }^{\#} p<0.05$ vs. ICH+SE group (one-way ANOVA followed by the Bonferroni post hoc test). (E) In the novel object recognition (NOR) test, mice in the ICH+EE group spent more time exploring the novel object than mice in the ICH+SE group. $\mathrm{n}=7$ mice/group. ${ }^{\star \star \star} p<0.001,{ }^{\star} p<0.05$ (one-way ANOVA followed by Bonferroni post hoc test). (F) Exposure to EE increased the discrimination index in the NOR test compared to exposure to SE. $\mathrm{n}=7$ mice/group. ${ }^{*} p<0.01$ vs. sham group, ${ }^{\# \#} p<0.01$ vs. ICH+SE group (one-way ANOVA followed by the Bonferroni post hoc test). Values are mean \pm SD. 


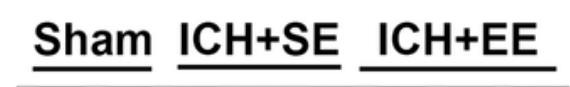

Nrf2

Tubulin
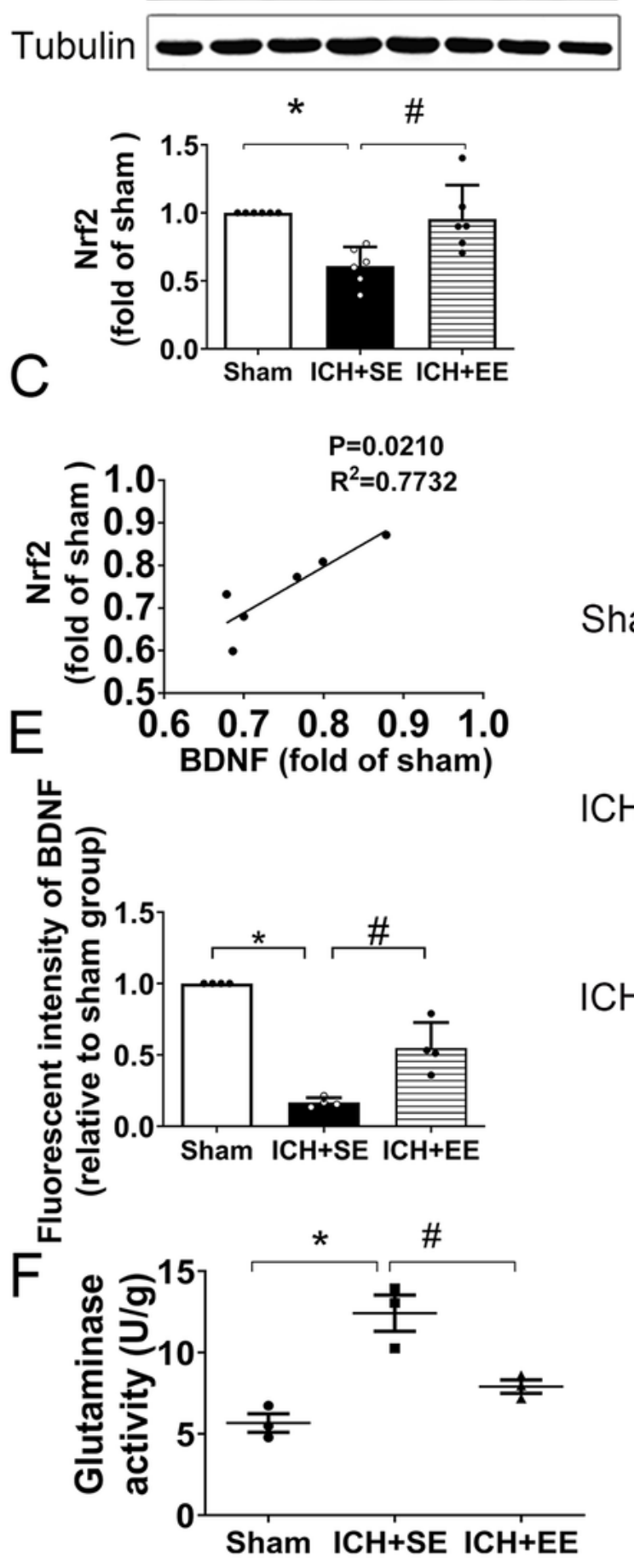

\section{B Sham ICH+SE ICH+EE}
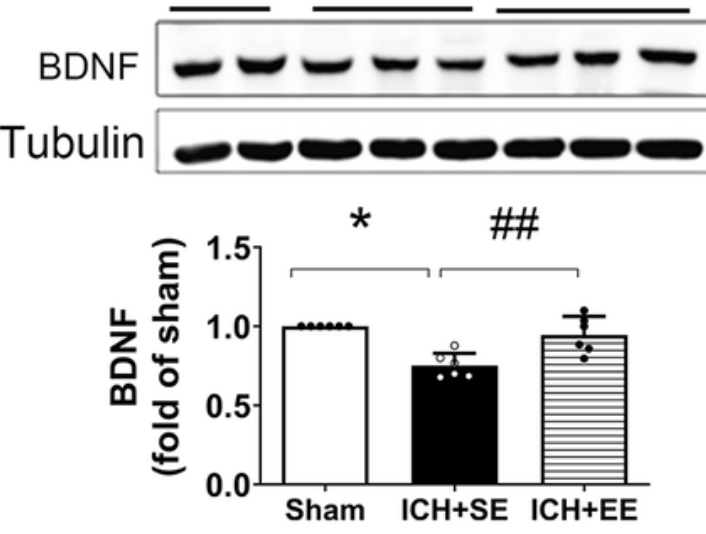

D BDNF DAPI MERGE

Sham
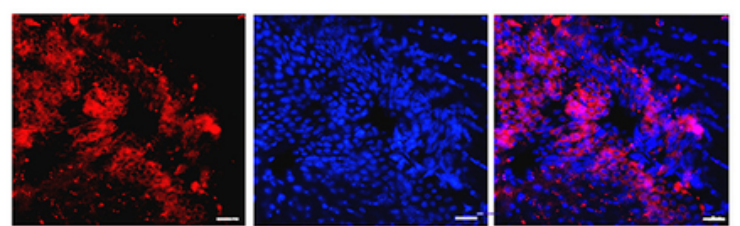

$\mathrm{ICH}+\mathrm{SE}$
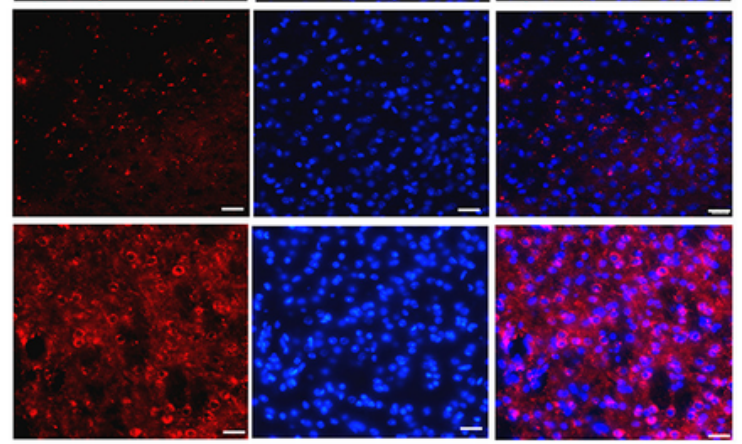

$G$

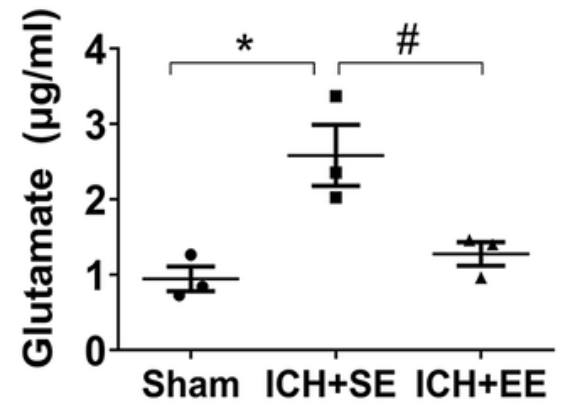

Figure 6

An enriched environment (EE) restores Nrf2 and BDNF expression and blocks glutaminase activity in mice with ICH. (A and B) Western blot analysis of Nrf2 and BDNF expression in the perihematomal tissue on day 28 after $\mathrm{ICH}$. Exposure to EE significantly increased Nrf2 and BDNF expression compared to exposure to the standard environment (SE). $\mathrm{n}=6$ mice/group. $\mathrm{F}=10.58,14.14$, respectively, ${ }^{\star *} p<0.01$ vs. sham group, " $p<0.05$, "\# $p<0.01$ vs. ICH+SE group (one-way ANOVA followed by the Bonferroni post hoc test). 
(C) Correlation between Nrf2 and BDNF expression. $\mathrm{n}=6$ mice/group, Spearman's test. $\mathrm{R}^{2}=0.7732$. (D) Representative immunofluorescence staining of BDNF in the perihematomal tissue on day 28. Scale bar $=100 \mu \mathrm{m}$. (E) Quantification of the fluorescence of BDNF in the perihematomal area. $n=3-4$ mice/group. $\mathrm{F}=31.57,{ }^{\star} p<0.05$ vs. sham group, ${ }^{\#} p<0.05$ vs. ICH+SE group (one-way ANOVA followed by the Bonferroni post hoc test). (F) Glutaminase activity in the perihematomal brain tissue on day 28. $n=3$ mice/group. ${ }^{* \star} p<0.01$ vs. sham group, ${ }^{*} p<0.05$ vs. ICH group (one-way ANOVA followed by the Bonferroni post hoc test). (G) Exposure to EE reduced glutamate levels in mice after ICH. $\mathrm{n}=3$ mice/group. $\mathrm{F}=20.45,10.51$, respectively, ${ }^{*} p<0.05 \mathrm{vs}$. sham group, ${ }^{*} p<0.05 \mathrm{vs}$. ICH group (one-way ANOVA followed by the Bonferroni post hoc test).

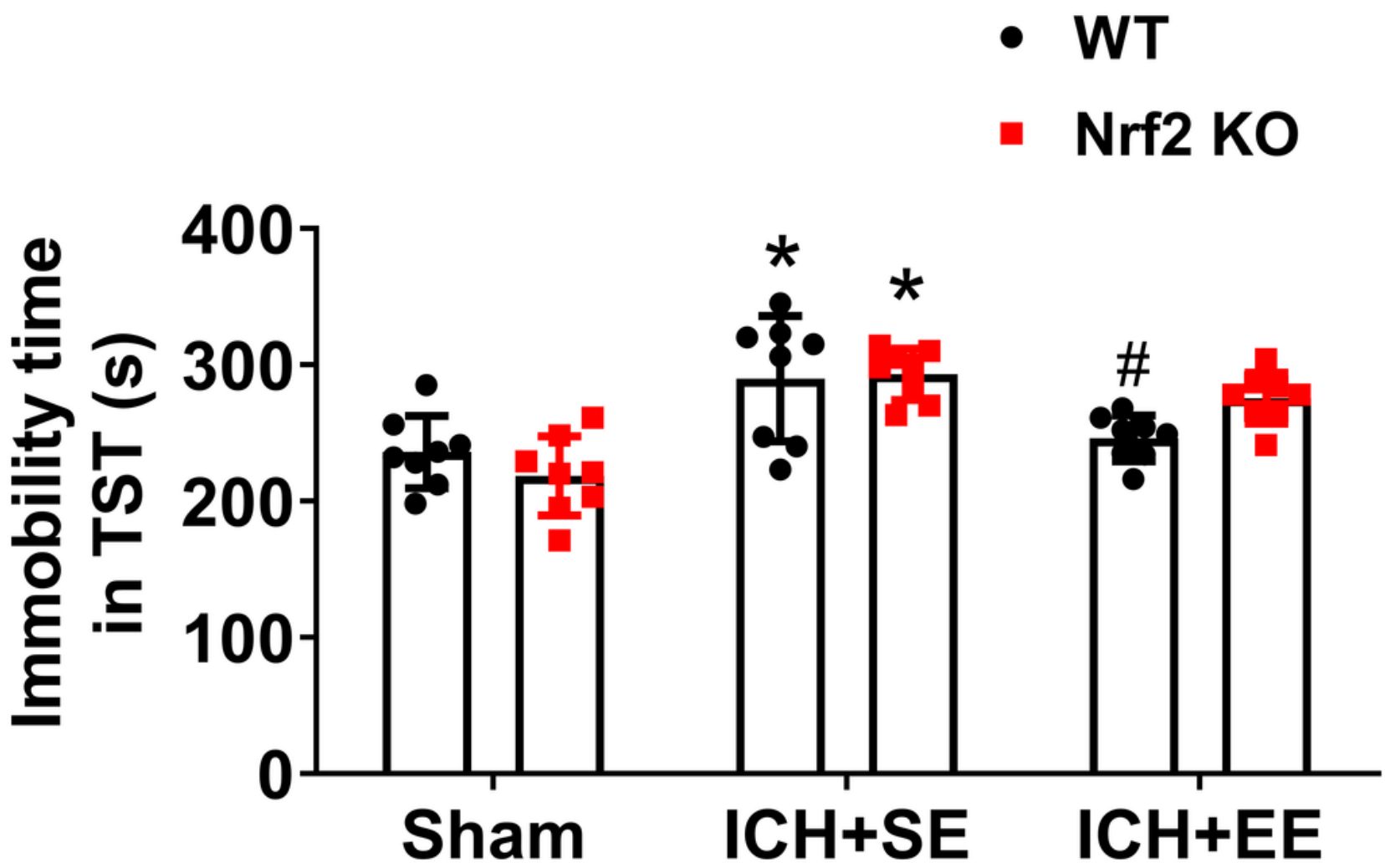

Figure 7

An enriched environment (EE) does not mitigate depression-like behaviors in $\mathrm{Nrf2}^{-1-}$ mice with $\mathrm{ICH}$. (A) The immobility time in the TST did not differ between $\mathrm{Nrf2}^{-/-} \mathrm{ICH}$ mice exposed to EE and SE. n=8-10 mice/group. $\mathrm{F}=1.024,{ }^{\star} p<0.05$ vs. sham group, ${ }^{\#} p<0.05$ vs. ICH+SE group (one-way ANOVA followed by the Bonferroni post hoc test). 


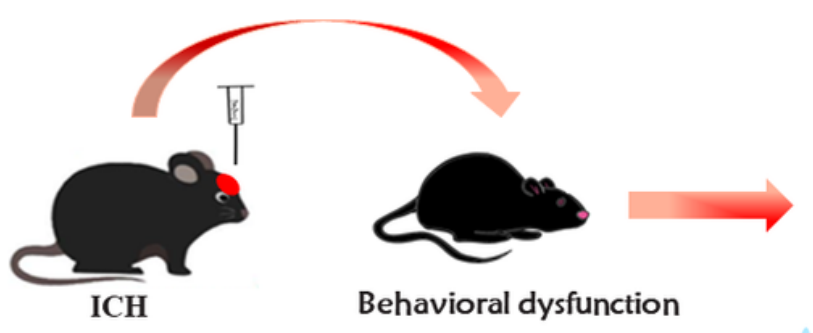

Long-term neurologic deficits

Depressive and anxiety-like behaviors

Spatial learning and memory dysfunction

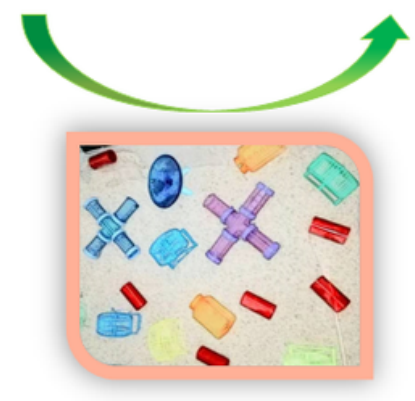

Enriched environment (EE)

Days 1-28

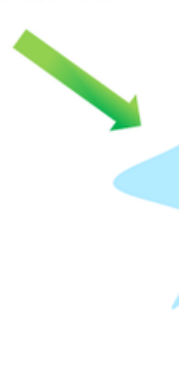

